\title{
Evaluating the Community Land Model (CLM4.5) at a coniferous forest site in northwestern United States using flux and carbon-isotope measurements
}

\author{
Henrique F. Duarte ${ }^{1}$, Brett M. Raczka ${ }^{2}$, Daniel M. Ricciuto ${ }^{3}$, John C. Lin ${ }^{1}$, Charles D. Koven ${ }^{4}$, Peter E. Thornton ${ }^{3}$, \\ David R. Bowling ${ }^{2}$, Chun-Ta Lai ${ }^{5}$, Kenneth J. Bible ${ }^{6}$, and James R. Ehleringer ${ }^{2}$ \\ ${ }^{1}$ Department of Atmospheric Sciences, University of Utah, Salt Lake City, 84112, USA \\ ${ }^{2}$ Department of Biology, University of Utah, Salt Lake City, 84112, USA \\ ${ }^{3}$ Oak Ridge National Laboratory, Oak Ridge, 37831, USA \\ ${ }^{4}$ Lawrence Berkeley National Laboratory, Berkeley, 94720, USA \\ ${ }^{5}$ Department of Biology, San Diego State University, San Diego, 92182, USA \\ ${ }^{6}$ United States Forest Service, Pacific Northwest Research Station, Corvallis, 97331, USA
}

Correspondence to: Henrique F. Duarte (h.duarte@utah.edu)

Received: 17 October 2016 - Discussion started: 21 October 2016

Revised: 20 June 2017 - Accepted: 16 August 2017 - Published: 28 September 2017

\begin{abstract}
Droughts in the western United States are expected to intensify with climate change. Thus, an adequate representation of ecosystem response to water stress in land models is critical for predicting carbon dynamics. The goal of this study was to evaluate the performance of the Community Land Model (CLM) version 4.5 against observations at an old-growth coniferous forest site in the Pacific Northwest region of the United States (Wind River AmeriFlux site), characterized by a Mediterranean climate that subjects trees to water stress each summer. CLM was driven by site-observed meteorology and calibrated primarily using parameter values observed at the site or at similar stands in the region. Key model adjustments included parameters controlling specific leaf area and stomatal conductance. Default values of these parameters led to significant underestimation of gross primary production, overestimation of evapotranspiration, and consequently overestimation of photosynthetic ${ }^{13} \mathrm{C}$ discrimination, reflected in reduced ${ }^{13} \mathrm{C}:{ }^{12} \mathrm{C}$ ratios of carbon fluxes and pools. Adjustments in soil hydraulic parameters within CLM were also critical, preventing significant underestimation of soil water content and unrealistic soil moisture stress during summer. After calibration, CLM was able to simulate energy and carbon fluxes, leaf area index, biomass stocks, and carbon isotope ratios of carbon fluxes and pools in reasonable agreement with site observations. Overall, the cali-
\end{abstract}

brated CLM was able to simulate the observed response of canopy conductance to atmospheric vapor pressure deficit (VPD) and soil water content, reasonably capturing the impact of water stress on ecosystem functioning. Both simulations and observations indicate that stomatal response from water stress at Wind River was primarily driven by VPD and not soil moisture. The calibration of the Ball-Berry stomatal conductance slope $\left(m_{\mathrm{bb}}\right)$ at Wind River aligned with findings from recent CLM experiments at sites characterized by the same plant functional type (needleleaf evergreen temperate forest), despite significant differences in stand composition and age and climatology, suggesting that CLM could benefit from a revised $m_{\mathrm{bb}}$ value of 6 , rather than the default value of 9 , for this plant functional type. Conversely, Wind River required a unique calibration of the hydrology submodel to simulate soil moisture, suggesting that the default hydrology has a more limited applicability. This study demonstrates that carbon isotope data can be used to constrain stomatal conductance and intrinsic water use efficiency in CLM, as an alternative to eddy covariance flux measurements. It also demonstrates that carbon isotopes can expose structural weaknesses in the model and provide a key constraint that may guide future model development. 


\section{Introduction}

The frequency, duration, and severity of droughts are expected to increase in the 21st century with climate change (Burke et al., 2006; Sheffield and Wood, 2008; Dai, 2013; Prein et al., 2016). In the western United States in particular, the combination of warmer temperature, larger vapor pressure deficit (VPD), reduced snowfall and snow pack, earlier snow melt, and extended growing season length is expected to lead to an intensification of water stress during the summer (Boisvenue and Running, 2010; Spies et al., 2010; Swain and Hayhoe, 2015; Fyfe et al., 2017). In this drying scenario, an accurate representation of ecosystem response to water stress in land models is critical for projecting carbon dynamics (and climate) into the future.

The land carbon and water cycles are coupled by the plant stomata through $\mathrm{CO}_{2}$ uptake (photosynthesis) and water vapor loss (transpiration). While stomatal conductance responds to atmospheric vapor pressure deficit, soil moisture, and various other environmental factors, its modeling still represents a major challenge for the scientific community (Damour et al., 2010). Many stomatal conductance models have been proposed, including different approaches to account for water stress, but each model is subject to its own limitations (Damour et al., 2010; Miner et al., 2017; Sperry et al., 2017). Traditionally, stomatal conductance models have been calibrated through leaf- to canopy-level observations of water exchange.

Stable carbon isotopes provide an alternative observation to constrain stomatal conductance and offer an opportunity for model evaluation and improvement. During photosynthesis, plants discriminate against the heavier stable isotope of carbon $\left({ }^{13} \mathrm{C}\right)$ in favor of the lighter, more abundant ${ }^{12} \mathrm{C}$ stable isotope. This discrimination in $\mathrm{C}_{3}$ plants, expressed as $\Delta=\left[\left(R_{\text {air }} / R_{\text {plant }}\right)-1\right] \times 1000(\% o)$, where $R_{\text {air }}$ and $R_{\text {plant }}$ are the ${ }^{13} \mathrm{C}:{ }^{12} \mathrm{C}$ isotope ratios of atmospheric $\mathrm{CO}_{2}$ and plant assimilated carbon, respectively, can be estimated according to the model proposed by Farquhar and Richards (1984) as

$\Delta=a+(b-a) c_{\mathrm{i}} / c_{\mathrm{a}}$,

where $c_{\mathrm{i}} / c_{\mathrm{a}}$ is the ratio of intracellular $\mathrm{CO}_{2}$ concentration to atmospheric $\mathrm{CO}_{2}$ concentration, $a$ is the ${ }^{13} \mathrm{C}$ discrimination associated with the process of $\mathrm{CO}_{2}$ diffusion through the stomata, and $b$ is the ${ }^{13} \mathrm{C}$ discrimination associated with the process of assimilation of $\mathrm{CO}_{2}$ via rubisco $(a \approx 4.4 \%$ o and $b \approx 27 \%$; Farquhar et al., 1989). The $c_{\mathrm{i}} / c_{\mathrm{a}}$ ratio correlates negatively with leaf intrinsic water use efficiency (iWUE), defined as the ratio of net leaf assimilation to stomatal conductance (Farquhar et al., 1989). Under water stress, $\mathrm{C}_{3}$ plants tend to reduce stomatal conductance and increase water use efficiency, leading to reductions in $c_{\mathrm{i}} / c_{\mathrm{a}}$ and ${ }^{13} \mathrm{C}$ discrimination, affecting the carbon isotope ratio $\left(\delta^{13} \mathrm{C}\right)$ of photosynthesis and consequently of carbon pools and respiration. Experimental studies have shown, for instance, correlations between the $\delta^{13} \mathrm{C}$ of ecosystem respiration and soil water content (SWC), atmospheric vapor pressure deficit, and precipitation. Bowling et al. (2008) and Brüggemann et al. (2011) present extensive reviews of experimental results on the link between environmental factors and the isotopic signature of carbon pools and fluxes, demonstrating that isotopic measurements provide insights into the response of stomatal conductance and iWUE to water stress. Furthermore, stable carbon isotopes have been used to partition photosynthetic and respiration fluxes from flux tower data (e.g., Wehr and Saleska, 2015) and to identify the strength of land and ocean sinks (e.g., Alden et al., 2010; van der Velde et al., 2013).

Photosynthetic ${ }^{13} \mathrm{C}$ discrimination is represented in biospheric models including the stable-isotope-enabled land surface model (ISOLSM) (Riley et al., 2002), the Simple Biosphere ( $\mathrm{SiB}$ ) model (Suits et al., 2005), the Lund-PotsdamJena (LPJ) dynamic global vegetation model (Scholze et al., 2003, 2008), the Land Surface Processes and Exchanges model of the University of Bern (LPX-Bern) (Spahni et al., 2013; Stocker et al., 2013), the hybrid SiB-CASA (combining biophysics from $\mathrm{SiB}$ and biochemistry from the Carnegie-Ames-Stanford Approach model) (van der Velde et al., 2013, 2014), and the Community Land Model (CLM) (Oleson et al., 2013).

Modeling studies have shown that stable carbon isotopes provide a constraint upon stomatal conductance (Aranibar et al., 2006; Raczka et al., 2016; Mao et al., 2016). Aranibar et al. (2006) evaluated the performance of ISOLSM at the Metolius Old Pine AmeriFlux site and were able to calibrate the slope of the stomatal conductance equation $\left(m_{\mathrm{bb}}\right.$ in the Ball-Berry stomatal conductance model; see Eq. 2) with the aid of foliar $\delta^{13} \mathrm{C}$ data measured at the site. Raczka et al. (2016) evaluated photosynthetic ${ }^{13} \mathrm{C}$ discrimination in CLM version 4.5 (CLM4.5) against $\delta^{13} \mathrm{C}$ observations of photosynthesis and biomass at the Niwot Ridge AmeriFlux site and found the model to perform poorly with its default nitrogen limitation approach, resulting in overestimation of stomatal conductance and ${ }^{13} \mathrm{C}$ discrimination. By using an alternative approach in which a nitrogen downscaling factor is directly applied to $V_{\text {cmax25 }}$ (maximum rate of carboxylation at $25^{\circ} \mathrm{C}$ ), they found significant improvement in the simulations, but with results still suggesting that a smaller $m_{\mathrm{bb}}$ value (they used the default $\mathrm{C}_{3}$ value, $m_{\mathrm{bb}}=9$ ) would better simulate the site observations. Mao et al. (2016) evaluated CLM4.0 at a loblolly pine site in Tennessee, USA, and were able to adequately simulate the observed biomass $\delta^{13} \mathrm{C}$ values with an optimized $m_{\mathrm{bb}}$ value of 5.6. Keller et al. (2017) used a global tree-ring $\delta^{13} \mathrm{C}$ data set to evaluate the 20th century trend in photosynthetic ${ }^{13} \mathrm{C}$ discrimination and iWUE as modeled by CLM4.5 and LPX-Bern. LPX-Bern was found to perform well, while CLM simulated a significantly stronger increase (decrease) in iWUE $\left({ }^{13} \mathrm{C}\right.$ discrimination) than that indicated by the tree-ring data. The default CLM parameterization and configuration were used in their study. Keller et al. (2017) suggested that the model-data mismatch was asso- 
ciated with the stomatal conductance parameterization $\left(m_{\mathrm{bb}}\right.$ in particular) and the shortcomings of the nitrogen limitation scheme.

The present study focuses on CLM - the land component of the Community Earth System Model (CESM), a fully coupled global climate model widely used by the scientific community (http://www.cesm.ucar.edu/publications/) - and further evaluates the performance of its latest release (CLM4.5 - hereafter referred simply as CLM; Oleson et al., 2013; http: //www.cesm.ucar.edu/models/cesm1.2/) against observations at a coniferous forest site in the Pacific Northwest region of the United States, with particular attention to the simulation of stomatal conductance and its response to water stress. The study site, Wind River, is part of the AmeriFlux eddy covariance network. Wind River is an old-growth forest ( 500 years) characterized by a Mediterranean climate, due to which trees are naturally subject to water stress each summer. The combination of long-term measurements of energy and carbon fluxes, meteorology, biological variables, and stable carbon isotope ratios makes the site a good choice for evaluating carbon cycle and carbon isotope components of CLM. In addition to energy flux observations that allow for the estimation of canopy conductance, this study leverages the recent inclusion of photosynthetic ${ }^{13} \mathrm{C}$ discrimination within CLM and also uses $\delta^{13} \mathrm{C}$ observations to better diagnose the simulation of stomatal conductance at the site. We test whether a reduced stomatal conductance at similar needleleaf evergreen temperate forest sites (Mao et al., 2016; Raczka et al., 2016) is appropriate for Wind River. This study also provides further investigation on the nitrogen limitation issue identified by Raczka et al. (2016) and the adequacy of the default parameters used in CLM, especially those regulating stomatal conductance. We test whether the calibration scheme (optimized parameters, nitrogen limitation) proposed by Raczka et al. (2016) for Niwot Ridge is appropriate for Wind River. By comparing the results at Wind River against those at different sites characterized by the same plant functional type (needleleaf evergreen temperate tree) but with different stand composition and age and climatology (Mao et al., 2016; Raczka et al., 2016), this study also seeks to identify general improvements in model parameterization.

\section{Material and methods}

This section provides a description of CLM, focusing on key formulations of relevance to the present study (Sect. 2.1), followed by a description of the study site (Sect. 2.2), the eddy covariance and meteorological data sets used to drive and assess the model (Sect. 2.3), the carbon isotope data sets used to assess the photosynthetic ${ }^{13} \mathrm{C}$ discrimination in CLM (Sect. 2.4), and also a description of the CLM configuration, simulations performed, and calibration of model parameters (Sect. 2.5 and 2.6). Section 2.7 describes the methodology used in the calculation of canopy conductance values from eddy covariance observations, which are compared against simulated values as a way to assess the model skill in simulating leaf stomatal conductance.

\subsection{Model description}

This section focuses on describing CLM's approach to the simulation of stomatal conductance and photosynthetic ${ }^{13} \mathrm{C}$ discrimination, key aspects of this study. For a full description of the model, the reader is referred to Oleson et al. (2013).

In CLM, leaf stomatal conductance $\left(g_{\mathrm{s}}\right)$ is calculated based on the Ball-Berry model as described by Collatz et al. (1991) and implemented by Sellers et al. (1996) in the SiB2 model:

$g_{\mathrm{s}}=m_{\mathrm{bb}} \frac{A_{\mathrm{n}}\left(\beta_{t}\right)}{c_{\mathrm{s}} / P_{\mathrm{atm}}} h_{\mathrm{s}}+b_{\mathrm{bb}} \beta_{t}$,

where $A_{\mathrm{n}}\left(\beta_{t}\right)$ is the potential net leaf photosynthesis (without nitrogen limitation) as a function of a soil moisture stress factor $\left(\beta_{t}\right), c_{\mathrm{S}}$ is the $\mathrm{CO}_{2}$ partial pressure at the leaf surface, $P_{\text {atm }}$ is the atmospheric pressure, $h_{\mathrm{s}}$ is the relative humidity at the leaf surface (defined as the ratio of vapor pressure at the leaf surface to saturation vapor pressure inside the leaf at vegetation temperature $T_{\mathrm{V}}$ ), $m_{\mathrm{bb}}$ is a slope coefficient, and $b_{\text {bb }}$ corresponds to the minimum stomatal conductance in the original Ball-Berry model. The soil moisture stress factor $\beta_{t}$ is defined as

$\beta_{t}=\sum_{i} w_{i} r_{i}$

where $r_{i}$ is the root fraction at soil layer $i$ and $w_{i}$ is a corresponding plant wilting factor. The former is defined as (Oleson et al., 2013)

$r_{i}=0.5\left(e^{-r_{\mathrm{a}} z_{h, i-1}}+e^{-r_{\mathrm{b}} z_{h, i-1}}\right)-0.5 \alpha\left(e^{-r_{\mathrm{a}} z_{h, i}}+e^{-r_{\mathrm{b}} z_{h, i}}\right)$,

where $z_{h, i}(\mathrm{~m})$ is the depth from the soil surface to the interface between layers $i$ and $i+1\left(z_{h, 0}=0\right.$ corresponds to the soil surface), $r_{\mathrm{a}}$ and $r_{\mathrm{b}}$ are root distribution parameters $\left(\mathrm{m}^{-1}\right), \alpha=1$ for $1 \leq i<N_{\text {levsoi }}$, and $\alpha=0$ for $i=N_{\text {levsoi }}$ ( $N_{\text {levsoi }}$ is the number of soil layers). The plant wilting factor for soil layer $i$ is defined as (Oleson et al., 2013)

$$
w_{i}= \begin{cases}\frac{\Psi_{\mathrm{c}}-\Psi_{i}}{\Psi_{\mathrm{c}}-\Psi_{\mathrm{o}}}\left[\frac{\theta_{\mathrm{sat}, i}-\theta_{\mathrm{ice}, i}}{\theta_{\mathrm{sat}, i}}\right] \leq 1 & \text { for } T_{i}>T_{\mathrm{f}}-2 \\ 0 & \text { and } \theta_{\mathrm{liq}, i}>0 \\ 0 & \text { for } T_{i} \leq T_{\mathrm{f}}-2 \\ & \text { or } \theta_{\mathrm{liq}, i}=0\end{cases}
$$

where $\Psi_{i}$ is the soil water matric potential, $\Psi_{\mathrm{c}}$ and $\Psi_{\mathrm{o}}$ are the soil water potential when stomata are fully closed or fully open, respectively $\left(\Psi_{\mathrm{c}}=-255000 \mathrm{~mm}\right.$ and $\Psi_{\mathrm{o}}=$ $-66000 \mathrm{~mm}$ for the needleleaf evergreen temperate tree plant functional type, hereafter referred simply as NETT 
PFT), $\theta_{\mathrm{sat}, i}$ is the saturated volumetric water content, $\theta_{\text {ice }, i}$ is the volumetric ice content, $\theta_{\mathrm{liq}, i}$ is the volumetric liquid water content, $T_{i}$ is the soil layer temperature, and $T_{\mathrm{f}}=273.15 \mathrm{~K}$ is the freezing temperature of water. The sum in Eq. (3) is defined over the entire soil column, resulting in $\beta_{t}$ values from 0 (maximum soil moisture stress) to 1 (no soil moisture stress). In CLM's implementation of the Ball-Berry model (Eq. 2), $\beta_{t}$ is used to downscale $b_{\mathrm{bb}}$, directly impacting $g_{\mathrm{s}} \cdot \beta_{t}$ also indirectly impacts $g_{\mathrm{s}}$ through the $A_{\mathrm{n}}$ term, as $\beta_{t}$ is used to downscale the maximum rate of carboxylation $\left(\beta_{t} V_{\mathrm{cmax}}\right)$ and also leaf respiration $\left(\beta_{t} R_{d}\right)$ (Oleson et al., 2013).

Stomatal conductance $\left(g_{\mathrm{s}}\right)$ and $A_{\mathrm{n}}$ are solved separately for sunlit and shaded leaves. Canopy conductance $\left(G_{\mathrm{c}}\right)$ is given by

$G_{\mathrm{c}}=\frac{1}{r_{\mathrm{b}}+r_{\mathrm{s}}^{\text {sun }}} \mathrm{LAI}^{\text {sun }}+\frac{1}{r_{\mathrm{b}}+r_{\mathrm{s}}^{\text {sha }}} \mathrm{LAI}^{\text {sha }}$

and potential gross primary production $\left(\mathrm{GPP}_{\mathrm{pot}}\right.$, without nitrogen limitation) by

$\mathrm{GPP}_{\mathrm{pot}}=\left(A_{\mathrm{n}}^{\text {sun }}+R_{d}^{\text {sun }}\right) \mathrm{LAI}^{\text {sun }}+\left(A_{\mathrm{n}}^{\text {sha }}+R_{d}^{\text {sha }}\right) \mathrm{LAI}^{\text {sha }}$,

where $r_{\mathrm{b}}$ is the leaf boundary layer resistance, $r_{\mathrm{s}}=1 / g_{\mathrm{s}}$ is the leaf stomatal resistance, LAI is the leaf area index, and $R_{d}$ is the leaf-level respiration (sun and sha superscripts denote sunlit and shaded leaves, respectively). Photosynthetic parameters such as $V_{\mathrm{cmax} 25}$ are solved separately for sunlit and shaded leaves and their canopy scaling scheme is detailed in Oleson et al. (2013, Sect. 8.3).

Based on nitrogen availability and nitrogen requirements for allocation of new carbon tissue, CLM calculates actual gross primary production (GPP) as

$\mathrm{GPP}=\mathrm{GPP}_{\mathrm{pot}}(1-d)$.

The nitrogen down-regulation factor $(d)$ is defined as

$d=\frac{\mathrm{CF}_{\text {avail_alloc }}-\mathrm{CF}_{\text {alloc }}}{\mathrm{GPP}_{\text {pot }}}$,

where $\mathrm{CF}_{\text {avail_alloc }}$ is the carbon flux from photosynthesis, which is available to new-growth allocation and $\mathrm{CF}_{\text {alloc }}$ is the actual carbon allocation to new growth (limited by nitrogen availability). This implementation of nitrogen downregulation makes CLM a partially coupled model with respect to net leaf photosynthesis and stomatal conductance. Note that GPP is calculated via down-regulation (Eq. 8) after the solution for $A_{\mathrm{n}}$ and $g_{\mathrm{s}}$ is obtained. Modeled $g_{\mathrm{s}}$ remains consistent with $A_{\mathrm{n}}$ (potential, not actual net leaf photosynthesis).

The original implementation of ${ }^{13} \mathrm{C}$ in CLM was developed in consultation with Neil Suits (Suits et al., 2005) and is described in Oleson et al. (2013). Photosynthetic ${ }^{13} \mathrm{C}$ discrimination in CLM for $\mathrm{C}_{3}$ plants follows the model proposed by Farquhar and Richards (1984) (cf. Eq. 1):

$\Delta=4.4+22.6 c_{\mathrm{i}} / c_{\mathrm{a}}$.
CLM calculates the intracellular-to-atmospheric $\mathrm{CO}_{2}$ concentration ratio, $c_{\mathrm{i}} / c_{\mathrm{a}}$, in Eq. (10) as

$\frac{c_{\mathrm{i}}}{c_{\mathrm{a}}}=1-\frac{A_{\mathrm{n}}(1-d)}{c_{\mathrm{a}}}\left[\frac{1.4}{g_{\mathrm{b}}}+\frac{1.6}{g_{\mathrm{s}}}\right]$,

where $g_{\mathrm{b}}$ is the leaf boundary layer conductance. CLM does not account for mesophyll conductance (intracellular $\mathrm{CO}_{2}$ is assumed to be the same as intercellular $\mathrm{CO}_{2}$ ). Assuming $g_{\mathrm{b}} \gg g_{\mathrm{s}}$ (typically true for coniferous needles), Eq. (11) can be approximated by

$$
\begin{aligned}
\frac{c_{\mathrm{i}}}{c_{\mathrm{a}}} & \cong 1-\frac{1.6(1-d)}{c_{\mathrm{a}}}\left[\frac{A_{\mathrm{n}}}{g_{\mathrm{s}}}\right] \\
& \cong 1-\frac{1.6(1-d)}{c_{\mathrm{a}}} \mathrm{iWUE},
\end{aligned}
$$

where $\mathrm{iWUE}=A_{\mathrm{n}} / g_{\mathrm{s}}$ is the intrinsic water use efficiency. Note that $c_{\mathrm{i}} / c_{\mathrm{a}}$ and consequently $\Delta$ correlate negatively with iWUE. All other terms being constant in Eq. (12), an increase in iWUE is expected to result in a reduction of the photosynthetic ${ }^{13} \mathrm{C}$ discrimination, i.e., an increase in the assimilation of the heavier ${ }^{13} \mathrm{C}$ stable isotope relative to the lighter, more abundant ${ }^{12} \mathrm{C}$ stable isotope. Note also that $A_{\mathrm{n}}$ is multiplied by $(1-d)$ in Eqs. (11) and (12), making $c_{\mathrm{i}}$ consistent with the actual, nitrogen-limited GPP. However, it is important to highlight that $g_{\mathrm{s}}$ is consistent with $A_{\mathrm{n}}$ (potential net assimilation), not $A_{\mathrm{n}}(1-d)$ (actual net assimilation). The implications of this mismatch to the simulation of $\Delta$ are discussed in Raczka et al. (2016) and later in the present paper.

The carbon isotope ratio of the GPP flux $\left(\delta^{13} \mathrm{C}_{\mathrm{GPP}}\right)$ is calculated in CLM based on the prescribed $\delta^{13} \mathrm{C}$ of atmospheric $\mathrm{CO}_{2}$, the carbon assimilation and photosynthetic ${ }^{13} \mathrm{C}$ discrimination by sunlit and shaded leaves, and their respective LAIs. The $\delta^{13} \mathrm{C}$ of newly allocated carbon is the same as $\delta^{13} \mathrm{C}_{\mathrm{GPP}}$. The $\delta^{13} \mathrm{C}$ of the leaf carbon pool, for instance, depends on the allocation flux and its $\delta^{13} \mathrm{C}\left(\delta^{13} \mathrm{C}_{\mathrm{GPP}}\right)$ and the turnover time of the pool. CLM does not include any representation of post-photosynthetic ${ }^{13} \mathrm{C}$ discrimination.

\subsection{Site description}

The site for this study (Wind River) is part of the AmeriFlux eddy covariance network (Baldocchi et al., 2001), with a long record of meteorological, biological, surface flux (energy and carbon), and carbon isotope measurements for model assessment (1998-present). The site is located in the Pacific Northwest region of the United States, in the state of Washington $(45.8205,-121.9519 ; 371 \mathrm{~m}$ elevation; see Fig. 1). Wind River is characterized by an old-growth conifer forest dominated by Douglas fir (Pseudotsuga menziesii) and western hemlock (Tsuga heterophylla) trees, with a mean canopy height of $56 \mathrm{~m}$. Douglas fir trees are about 40-65 m high, corresponding to about $50 \%$ of the wood volume of the stand and $33 \%$ of the leaf area, while western hemlock trees are more numerous and smaller, corresponding to about $53 \%$ of 

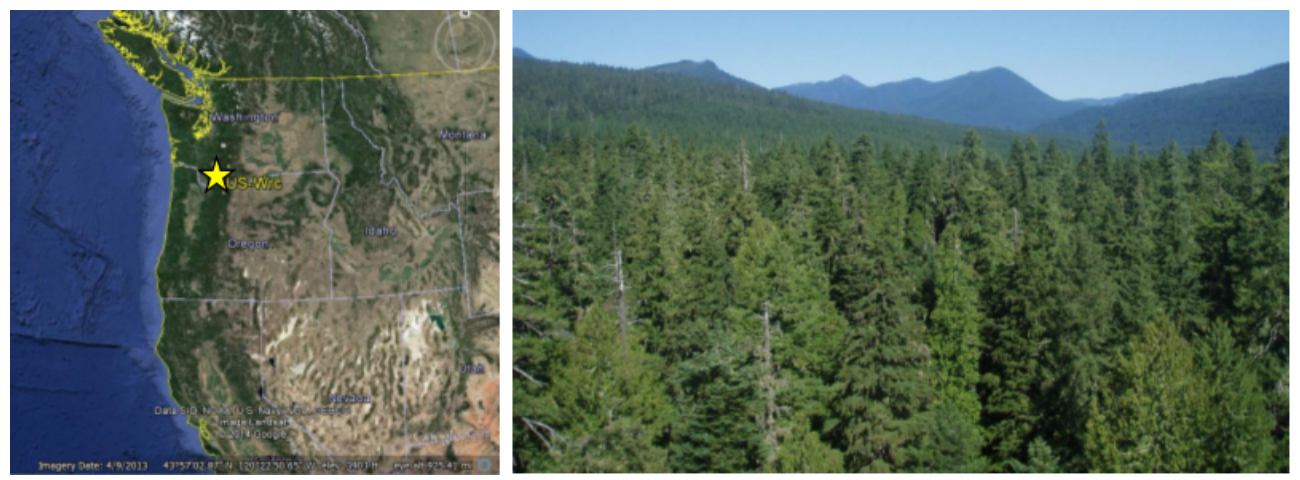

Figure 1. Location and view of the Wind River AmeriFlux site, US-Wrc (satellite image from Google Earth).

the leaf area of the stand (Unsworth et al., 2004; Parker et al., 2004). No significant disturbances have occurred at the site in the past $\sim 450-500$ years. The local climate is strongly seasonal, marked by dry summers and wet winters. The climate summary reported by Shaw et al. (2004) indicates a mean annual precipitation of $2223 \mathrm{~mm}$, with only $\approx 5 \%$ falling during June, July, and August. During winter, much of the precipitation falls as snow, and the average snowpack depth exceeds $100 \mathrm{~mm}$. The mean annual, January, and July air temperatures are $8.7 \pm 6.5,0.1 \pm 2.3$, and $17.7 \pm 1.7^{\circ} \mathrm{C}$, respectively.

\subsection{Eddy covariance and meteorological data}

Air temperature, relative humidity, wind speed, incident shortwave radiation, incident long-wave radiation, atmospheric pressure, and precipitation observed at the Wind River site from 1998 to 2006 were used to drive CLM. The time series were gap-filled using data from nearby towers and climate stations or interpolated in case of missing data. The gap-filled data product used to drive CLM in this study was created at Oak Ridge National Laboratory following the methodology described in Barr et al. (2013).

The L4 data set based on the eddy covariance observations (version V002, daily averages) was downloaded from the AmeriFlux repository at ftp://cdiac.ornl.gov/pub/ ameriflux/data/ (AmeriFlux data are currently hosted at http: //ameriflux.lbl.gov, see Wharton, 1998-2016). This data set contains friction-velocity-filtered, gap-filled, and partitioned fluxes and was used to assess the simulated surface fluxes of sensible heat $(H)$, latent heat (LE), and carbon, including GPP and ecosystem respiration (ER). The ER product was estimated according to the short-term temperature response of measured nighttime net ecosystem exchange (NEE) (Reichstein et al., 2005), and GPP was estimated as the difference between ER and NEE: i.e., ER - NEE. The gap-filled NEE values (and derived GPP and ER) using the marginal distribution sampling method (Reichstein et al., 2005) were used in this study.
Eddy covariance and meteorological data from the AmeriFlux L2 data product (version V007, 30 min averages) were used to calculate canopy conductance $\left(G_{\mathrm{c}}\right.$; see Sect. 2.7$)$ and atmospheric VPD. In the analysis, 30 min surface flux data were rejected during periods when the wind direction was in the $\left[45^{\circ}: 135^{\circ}\right]$ sector (same criterion used by Wharton et al., 2012), as the northeast-to-southeast wind sector is characterized by heterogeneous (age-fragmented) land cover. The data were averaged hourly prior to $G_{\mathrm{c}}$ and VPD calculation. L2 SWC data were also used in the analysis. Missing SWC data from the L2 data set in the year 2002 were replaced by respective L1 data (version Apr2013).

The AmeriFlux L2 data product (version V007, 30 min averages) was also used to assess the energy balance closure at the site. The energy balance ratio, $\mathrm{EBR}=(H+\mathrm{LE}) /\left(R_{\mathrm{n}}-\right.$ $G$ ), where $R_{\mathrm{n}}$ is net radiation and $G$ is soil heat flux, was calculated for dry season months (June to September) using 10:00-14:00 PST data and rejecting periods with rain or unfavorable wind direction ( $\left[45^{\circ}: 135^{\circ}\right]$ sector). With the available data, EBR could be calculated for the years of 1998 2001, 2004, and 2006.

\subsection{Carbon isotope data}

Estimated $\delta^{13} \mathrm{C}$ values of ER (Lai et al., 2005) and observed ${ }^{13} \mathrm{C}$ values of leaf tissue and soil organic matter (SOM) (Fessenden and Ehleringer, 2003) at Wind River were used to assess the photosynthetic ${ }^{13} \mathrm{C}$ discrimination in CLM. Lai et al. (2005) used an automated air sampling system, with inlets at $0.5 \mathrm{~m}$ above ground level and at 0.5 canopy height, collecting 15 flasks weekly during the growing season. Most of the flasks (13 out of 15) were dedicated to nighttime sampling (over a single night). The Keeling plot method was used to infer the weekly $\delta^{13} \mathrm{C}_{\mathrm{ER}}$ using the $\mathrm{CO}_{2}$ and $\delta^{13} \mathrm{CO}_{2}$ observations (for simplicity, the resulting $\delta^{13} \mathrm{C}_{\mathrm{ER}}$ values are referred to as observations in the text). The monthly averages (JuneNovember) from 2001 to 2003 reported by Lai et al. (2005) were used as references in the present study. Fessenden and Ehleringer (2003) conducted measurements of $\delta^{13} \mathrm{C}$ of bulk organic tissue from current-year needles of Tsuga hetero- 
phylla trees and seedlings at the top $(55 \mathrm{~m})$, middle $(25 \mathrm{~m})$, and bottom $(2 \mathrm{~m})$ of the canopy. They also conducted vertical profile measurements of $\delta^{13} \mathrm{C}$ of bulk soil organic carbon down to $20 \mathrm{~cm}$ depth. The measurements were performed on a 1-month to 2-month time interval. The values reported by Fessenden and Ehleringer (2003) for the growing season in 1999 and 2000 were used as references.

In the present study, both observed and modeled carbon isotope ratios were expressed as $\delta^{13} \mathrm{C}=\left(\frac{R_{x}}{R_{\text {std }}}-1\right) \times 1000$ (\%o), where $R_{x}$ is the ${ }^{13} \mathrm{C}:{ }^{12} \mathrm{C}$ isotope ratio of the carbon pool or flux of interest and $R_{\text {std }}$ is the ${ }^{13} \mathrm{C}:{ }^{12} \mathrm{C}$ isotope ratio of a standard reference material (Vienna Pee Dee Belemnite standard).

\subsection{CLM configuration and simulations}

CLM was run at site level using the Point CLM (PTCLM) scripting framework (see Kluzek, 2013), as in recent studies (e.g., Mao et al., 2016; Raczka et al., 2016). Land cover was defined as the needleleaf evergreen temperate tree plant functional type. The model was configured to use CLM4.5 physics and CLM4.5 carbon-nitrogen $(\mathrm{CN})$ biogeochemistry. The vertical soil carbon profile option was turned on, and the CENTURY carbon model was selected for the decomposition parameters. The nitrification and denitrification sub-model was switched off, as preliminary simulations indicated an excess of nitrogen availability and forest productivity when the respective module was active. Given that the Wind River site is characterized by an old-growth mature forest, no land-cover disturbance was considered in the simulations.

The model was spun-up in a two-stage process, using a preindustrial component set with a constant, preindustrial atmospheric $\mathrm{CO}_{2}$ concentration and $\delta^{13} \mathrm{CO}_{2}$ of $285 \mathrm{ppmv}$ and $-6.5 \%$, respectively. The model was run in accelerated decomposition mode for 600 years (first stage) and then in normal decomposition mode for 1000 years (second and final stage), using the local observed meteorological data (Sect. 2.3) from 1998 to 2006 to drive the model (continuously cycled). Following the spin-up process, a transient run (1850-2006) was performed with prescribed nitrogen deposition, atmospheric $\mathrm{CO}_{2}$ concentration, and atmospheric $\delta^{13} \mathrm{CO}_{2}$.

The transient atmospheric $\mathrm{CO}_{2}$ concentrations used in this study were based on the CMIP5 recommendations for annual global mean values (Meinshausen et al., 2011). The transient atmospheric $\delta^{13} \mathrm{CO}_{2}$ values used here were based on ice-core and flask measurements reported by Francey et al. (1999) (annual values in their spline fitting from 1850 to 1981) and flask measurements in Mauna Loa (annual averages from 1981 to 2006) by the Scripps $\mathrm{CO}_{2}$ program (Keeling et al., 2005), following a similar methodology as in Raczka et al. (2016) (note that, unlike in Raczka et al., 2016, here a seasonal cycle was not superimposed onto the time series). As in the spin-up process, the local observed mete- orological data from 1998 to 2006 were cycled during the transient run. The driver data and model years were aligned in a way to guarantee a perfect match between them during the final 9 years of the simulation (1998-2006).

\subsection{CLM calibration}

Initial simulations using the default parameters from CLM resulted in a poor representation of the carbon dynamics at the Wind River site (Figs. A5 and A6). GPP and forest biomass were significantly underestimated. The seasonality of ER was poorly represented and the simulated late-summer GPP was impacted by an underestimation of SWC, resulting from a poor representation of soil hydrology at the site. Furthermore, the modeled evapotranspiration values were significantly overestimated for the given values of GPP, i.e., the simulated water use efficiency was much lower than that observed. As a result of CLM's poor performance in the simulation of GPP and evapotranspiration, the modeled photosynthetic ${ }^{13} \mathrm{C}$ discrimination was found to be overestimated, reflected in reduced ${ }^{13} \mathrm{C}:{ }^{12} \mathrm{C}$ ratios of carbon fluxes and pools.

In order to improve the representation of the carbon dynamics at the site, key model parameters were calibrated as detailed in Appendix A and summarized in Table 1. The adjusted parameters were primarily based on biological measurements at Wind River or at similar stands in the Pacific Northwest. Parameters controlling specific leaf area and stomatal conductance were found to be critical to the simulation of GPP and evapotranspiration and were manually adjusted in a way to minimize the differences between model output and site observations (eddy covariance fluxes). The default soil hydraulic parameters used in CLM4.5 were found to be inadequate at Wind River, leading to severe underestimation of SWC and unrealistic soil moisture stress in the model during late summer. These parameters were reverted back to their default values in CLM4.0, with significant improvement in the representation of soil hydrology at the site. In an additional measure to reduce the unrealistic late-summer soil moisture stress in the model, root distribution was adjusted based on CLM's default parameter values for the broadleaf evergreen temperate tree plant functional type, shifting roots towards deeper soil layers (justified based on physical understanding of the site - see Appendix A8).

Bayesian parameter calibration is a common approach used in modeling studies to account for both the prior parameter distributions and more recent observations. In this case, a Bayesian calibration approach would be complicated by the current lack of prior parameter distributions within CLM in order to create a model ensemble and the computational expense of running a calibration. Commonly used techniques such as Markov chain Monte Carlo (MCMC) are prohibitively expensive with long CLM simulations, and more advanced techniques for calibration (e.g., using surrogate modeling approaches) are still under development. The simpler approach used here proved to be an effective method 
Table 1. Summary of changes in CLM parameters during the calibration process. The parameters listed, excluding $M, Q_{10}, m_{\mathrm{bb}}, b_{\mathrm{bb}}$, and soil hydraulic parameters, correspond to the needleleaf evergreen temperate tree plant functional type (NETT PFT).

\begin{tabular}{|c|c|c|c|c|}
\hline Parameter & Description & CLM name & $\begin{array}{l}\text { Default CLM } \\
\text { value }\end{array}$ & $\begin{array}{l}\text { Calibrated CLM } \\
\text { value }\end{array}$ \\
\hline$A_{\mathrm{S}: 1}$ & 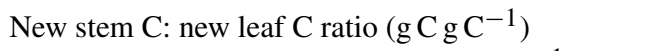 & stem_leaf & Dynamic & 2 \\
\hline$A_{\mathrm{fr}: 1}$ & New fine root $\mathrm{C}$ : new leaf $\mathrm{C}$ ratio $\left(\mathrm{g} \mathrm{C} \mathrm{g} \mathrm{C}^{-1}\right)$ & froot_leaf & 1 & 0.385 \\
\hline $\mathrm{CN}_{1}$ & Leaf $\mathrm{C}: \mathrm{N}$ ratio $\left(\mathrm{gC} \mathrm{g} \mathrm{N}^{-1}\right)$ & leafcn & 35 & 38.2 \\
\hline $\mathrm{CN}_{\text {llit }}$ & Leaf litter $\mathrm{C}: \mathrm{N}$ ratio $\left(\mathrm{g} \mathrm{C}^{-1}\right)$ & lflitcn & 70 & 76.4 \\
\hline $\mathrm{CN}_{\mathrm{fr}}$ & Fine root $\mathrm{C}: \mathrm{N}$ ratio $\left(\mathrm{g} \mathrm{C} \mathrm{g} \mathrm{N}^{-1}\right)$ & frootcn & 42 & 64.7 \\
\hline$\tau_{1}$ & Leaf longevity (yr) & leaf_long & 3 & 5 \\
\hline$r_{\mathrm{b}}$ & Root distribution parameter $\left(\mathrm{m}^{-1}\right)$ & rootb_par & 2 & 1 \\
\hline $\mathrm{SLA}_{0}$ & Specific leaf area at canopy top $\left(\mathrm{m}^{2}\right.$ leaf $\left.\mathrm{g} \mathrm{C}^{-1}\right)$ & slatop & 0.010 & 0.006 \\
\hline$m$ & $\operatorname{SLA}(x)$ slope $\left(\mathrm{m}^{2}\right.$ ground $\left.\mathrm{g} \mathrm{C}^{-1}\right)$ & dsladlai & 0.00125 & 0.000985 \\
\hline$M$ & Plant mortality rate $\left(\% \mathrm{yr}^{-1}\right)$ & $a m$ & 2 & 1.5 \\
\hline$Q_{10}$ & $\begin{array}{l}\text { Temperature sensitivity coefficient of maintenance } \\
\text { respiration and decomposition }(-)\end{array}$ & $q 10$ & 1.5 & 2.5 \\
\hline $\begin{array}{l}\text { Soil hydraulic } \\
\text { parameters }\end{array}$ & Version used & $\begin{array}{l}\text { origflag (namelist } \\
\text { variable) }\end{array}$ & 0 (CLM4.5) & 1 (CLM4.0) \\
\hline$m_{\mathrm{bb}}$ & Ball-Berry equation slope (-) & mbbopt & 9 & 6 \\
\hline$b_{\mathrm{bb}}$ & Ball-Berry equation intercept $\left(\mu \mathrm{mol} \mathrm{m}{ }^{-2}\right.$ leaf $\left.\mathrm{s}^{-1}\right)$ & bbbopt & 10000 & 5000 \\
\hline
\end{tabular}

to improve model performance at the Wind River AmeriFlux site. The reader is referred to Appendix A for a more complete description of the parameters that were adjusted and the calibration approach used. All model results presented and discussed in Sects. 3 and 4, unless noted otherwise, are based on the optimized model.

\subsection{Canopy conductance}

Observed canopy conductance $\left(G_{\mathrm{c}}, \mathrm{m} \mathrm{s}^{-1}\right)$ was calculated by combining hourly tower data (see Sect. 2.3) with the Penmann-Monteith equation (Monteith, 1964) as in Wharton et al. (2012):

$G_{\mathrm{c}}=\left[\frac{\rho c_{p} \mathrm{VPD}}{\gamma \mathrm{LE}}+\frac{\left(\frac{\Delta_{\mathrm{sat}}}{\gamma}\right)\left(\frac{H}{\mathrm{LE}}\right)-1}{G_{\mathrm{a}}}\right]^{-1}$,

where $\rho$ and $c_{p}$ are the density and specific heat of air, respectively $\left(\mathrm{kg} \mathrm{m}^{-3}, \mathrm{~J} \mathrm{~kg}^{-1} \mathrm{~K}^{-1}\right)$, VPD is the atmospheric vapor pressure deficit $(\mathrm{kPa}), \mathrm{LE}$ is the latent heat flux $\left(\mathrm{W} \mathrm{m}^{-2}\right)$, $\Delta_{\text {sat }}$ is the slope of the saturation vapor pressure curve as a function of air temperature $\left(\mathrm{kPa} \mathrm{K}^{-1}\right), \gamma$ is the psychrometric constant $\left(\mathrm{kPa} \mathrm{K}^{-1}\right), H$ is the sensible heat flux $\left(\mathrm{W} \mathrm{m}^{-2}\right)$, and $G_{\mathrm{a}}=u_{*}^{2} / U$ is the aerodynamic conductance for momentum transfer $\left(\mathrm{m} \mathrm{s}^{-1}\right)$, where $u_{*}$ is the friction velocity and $U$ is the wind speed. Atmospheric pressure and air temperature data and the ideal gas law were later used to convert the $G_{\mathrm{c}}$ values to $\mathrm{mmol} \mathrm{m}{ }^{-2} \mathrm{~s}^{-1}$. The calculation of $G_{\mathrm{c}}$ was restricted to daytime hours (10:00-16:00 PST) and to the months of June to September (dry season). Rain events and periods with $\mathrm{LE}<5 \mathrm{~W} \mathrm{~m}^{-2}$ or relative humidity $>80 \%$ were disregarded. $G_{\mathrm{c}}$ values outside the interval of 0 to $1000 \mathrm{mmol} \mathrm{m}^{-2} \mathrm{~s}^{-1}$ were also disregarded.

For comparison against observations, modeled canopy conductance values were calculated using the same methodology described above, but using hourly CLM output ( $H$, LE, $u_{*}$ ) instead. An alternative would be to calculate canopy conductance directly by upscaling CLM's leaf stomatal conductance and leaf boundary layer conductance using LAI (Eq. 6). Canopy conductance values derived from both approaches were found to be strongly correlated. The Penmann-Monteith method was ultimately selected for the calculation of $G_{\mathrm{c}}$ in order to allow a more direct comparison between modeled and observed values. This comparison was done as a way to assess the performance of CLM in the simulation of leaf stomatal conductance.

\section{Results}

\subsection{Carbon pools and isotopic signatures}

Figure 2 shows modeled LAI, carbon stocks (leaf, fine root, coarse root, tree wood, and SOM carbon), and $\delta^{13} \mathrm{C}$ of leaf and SOM pools throughout the transient run (1850-2006). Before the transient run, the model was spun-up and successfully equilibrated under the defined preindustrial scenario, with LAI, carbon stocks, and leaf and SOM carbon isotope ratios reaching steady state (results not shown). The cyclic behavior exhibited in Fig. 2 is related to the driving meteorological data set, which was cycled throughout the simulation period (Sect. 2.5). 

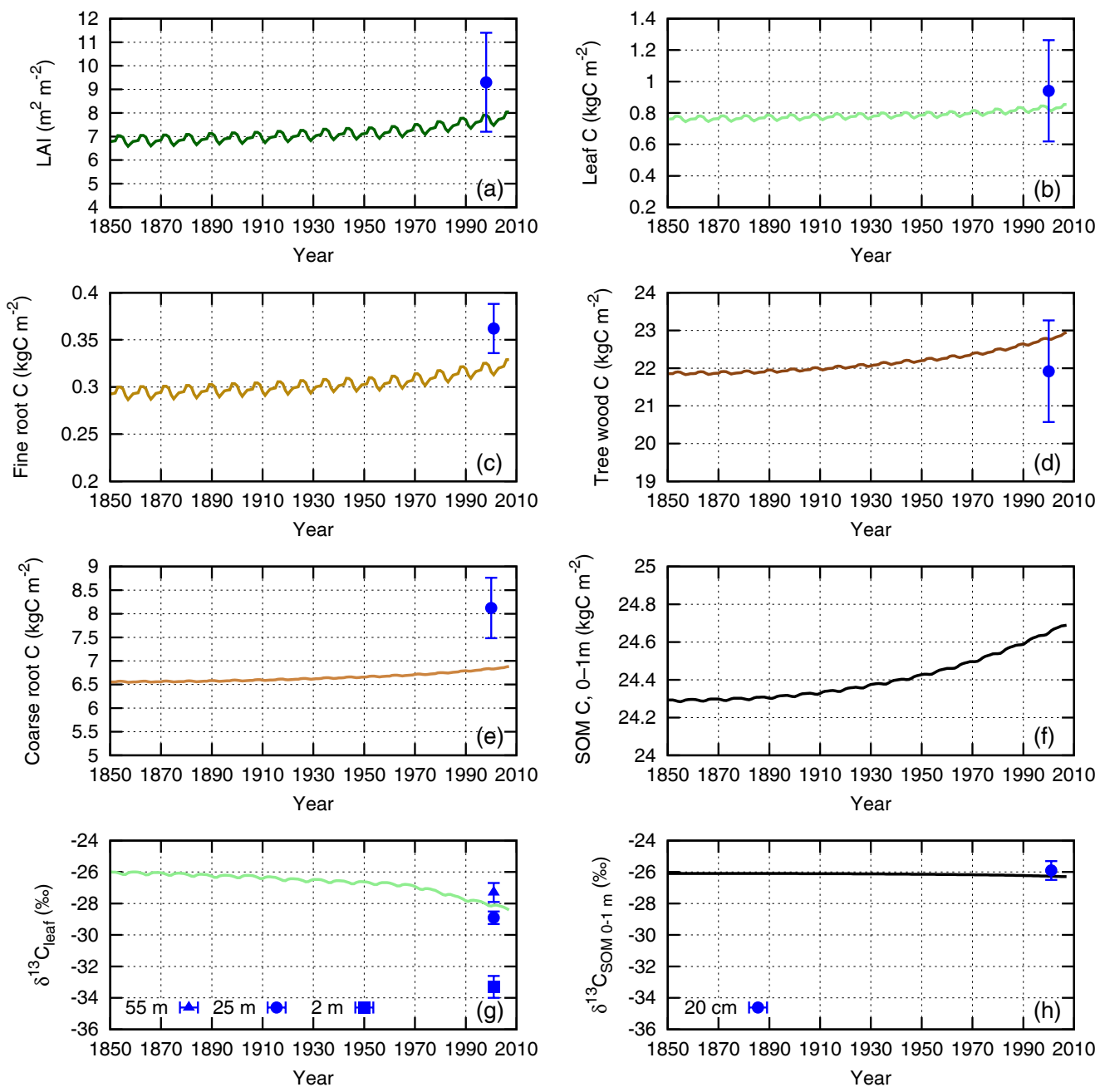

Figure 2. Modeled leaf area index (a), carbon stocks (b-f), and $\delta^{13} \mathrm{C}$ of leaf (g) and soil organic matter (h) during the transient run (lines) compared against site observations (points and error bars). Modeled values in panels (a-f) correspond to annual averages. Modeled $\delta^{13} \mathrm{C}$ values in panels (g) and (h) were calculated from annual averages of the respective ${ }^{13} \mathrm{C}$ and ${ }^{12} \mathrm{C}$ pools. Observations in panels (a-e) (average \pm SD) are from the AmeriFlux database (based on Thomas and Winner, 2000 and Harmon et al., 2004). Observations in panels (g) and (h) correspond to the average \pm SD of the measurements reported by Fessenden and Ehleringer (2003) in their Figs. $2 \mathrm{~b}$ and 3 (leaf $\delta^{13} \mathrm{C}$ at canopy top (55 m), middle $(25 \mathrm{~m})$, and bottom $(2 \mathrm{~m})$ and $\mathrm{SOM} \delta^{13} \mathrm{C}$ at $20 \mathrm{~cm}$ depth).

From 1850 to 2006, modeled LAI and carbon stocks (Fig. 2a-f) increased due to $\mathrm{CO}_{2}$ fertilization and increasing nitrogen deposition. Average values of LAI, leaf carbon, and tree wood carbon were in agreement with the reference values reported in the AmeriFlux database for the Wind River site. Modeled fine root and coarse root carbon were underestimated, but within 2 standard deviations from the reference values.

The $\delta^{13} \mathrm{C}$ of leaves and SOM was initialized in the model with a value of $-6 \%$ (default value in CLM, close to the preindustrial atmospheric $\delta^{13} \mathrm{CO}_{2}$ value of $-6.5 \%$ used in this study). During the model spin-up, in which constant preindustrial atmospheric $\delta^{13} \mathrm{CO}_{2}$ and $\mathrm{CO}_{2}$ concentration values were prescribed, the $\delta^{13} \mathrm{C}$ values stabilized at $\approx-26 \%$. During the transient simulation, the $\delta^{13} \mathrm{C}$ of both leaves (Fig. 2g) and SOM (Fig. 2h) decreased (the pools became isotopically "lighter"), mostly due to the decreasing atmospheric $\delta^{13} \mathrm{CO}_{2}$ values associated with the Suess effect (Keeling, 1979) but also due to the increasing atmospheric $\mathrm{CO}_{2}$ concentration values. The $\delta^{13} \mathrm{C}$ of leaves declined faster over the years than the $\delta^{13} \mathrm{C}$ of SOM, given the fact that leaves have a significantly shorter turnover time than SOM and therefore present a faster response to the changes in atmospheric $\delta^{13} \mathrm{CO}_{2}$ and $\mathrm{CO}_{2}$ concentration. Modeled $\delta^{13} \mathrm{C}$ of leaves compared well against the site observations for topand mid-canopy leaves $(-0.8$ and $+0.8 \%$ difference, respectively), and modeled $\delta^{13} \mathrm{C}$ of SOM (top $1 \mathrm{~m}$ of soil) com- 
pared well against site observations for SOM at $20 \mathrm{~cm}$ below ground $(-0.4 \%$ o difference).

It is important to clarify that CLM has leaf properties that vary continuously with canopy depth and that two leaf categories (sunlit and shaded leaves) are estimated dynamically at every time step, as a function of canopy structure and solar elevation angle (Thornton and Zimmerman, 2007). The modeled leaf $\delta^{13} \mathrm{C}$ output corresponds to the isotopic signature of the entire leaf carbon pool, which is calculated from both sunlit and shaded portions of the leaf canopy (see Sect. 2.1). The observed leaf $\delta^{13} \mathrm{C}$ values in Fig. $2 \mathrm{~g}$ correspond to measurements at canopy top $(55 \mathrm{~m})$, middle $(25 \mathrm{~m})$, and bottom $(2 \mathrm{~m})$. As pointed out by Fessenden and Ehleringer (2003), the decrease in the observed leaf $\delta^{13} \mathrm{C}$ values (i.e., increase in photosynthetic ${ }^{13} \mathrm{C}$ discrimination) with canopy depth can be explained by light reduction within the canopy. In principle, the observed mid-canopy values are expected to better represent the isotopic composition of leaves for the whole canopy, in comparison with the observed values at the two canopy extremes, especially given the larger amount of leaf biomass in the mid-canopy. However, considering how light is reduced within the canopy, the top-canopy $\delta^{13} \mathrm{C}$ value should still be representative of a significant fraction of the canopy as well; thus, the whole canopy $\delta^{13} \mathrm{C}$ is expected to lay somewhere in between the top- and mid-canopy values. As shown in Fig. $2 \mathrm{~g}$, the modeled $\delta^{13} \mathrm{C}$ of the leaf carbon pool was the average between the observed values at canopy top and middle.

The overall agreement between the observed and modeled carbon isotope ratios indicates that CLM had skill in simulating the balance between assimilation and stomatal conductance and the associated photosynthetic ${ }^{13} \mathrm{C}$ discrimination. The adjustment of the parameters controlling stomatal conductance in the model ( $m_{\mathrm{bb}}$ and $b_{\mathrm{bb}}-$ see Sect. 2.6, Table 1 and Appendix A9) to improve the simulation of evapotranspiration had a significant impact on the simulation of photosynthetic ${ }^{13} \mathrm{C}$ discrimination. When using the default parameter values (resulting in significantly higher stomatal conductance values), the modeled values of $\delta^{13} \mathrm{C}$ in leaves and SOM were generally 2-3\% lower (Fig. A1), departing from site observations.

\subsection{Energy and carbon fluxes}

Modeled energy and carbon fluxes are compared against daily-averaged observations in Fig. 3 for the period between 1998 and 2006. "Observed" GPP and ER values were obtained from applying a partitioning model to NEE measurements (Sect. 2.3), but are referred to as observations in the text.

Modeled LE values were close to observations, with a mean bias error (MBE) of $\approx-3 \mathrm{~W} \mathrm{~m}^{-2}$ and a RMSE of $\approx 20 \mathrm{~W} \mathrm{~m}^{-2}$. The adjustment of the stomatal conductance parameters $m_{\mathrm{bb}}$ and $b_{\mathrm{bb}}$ (Table 1) was fundamental in modifying the LE simulations. When using the default parame-
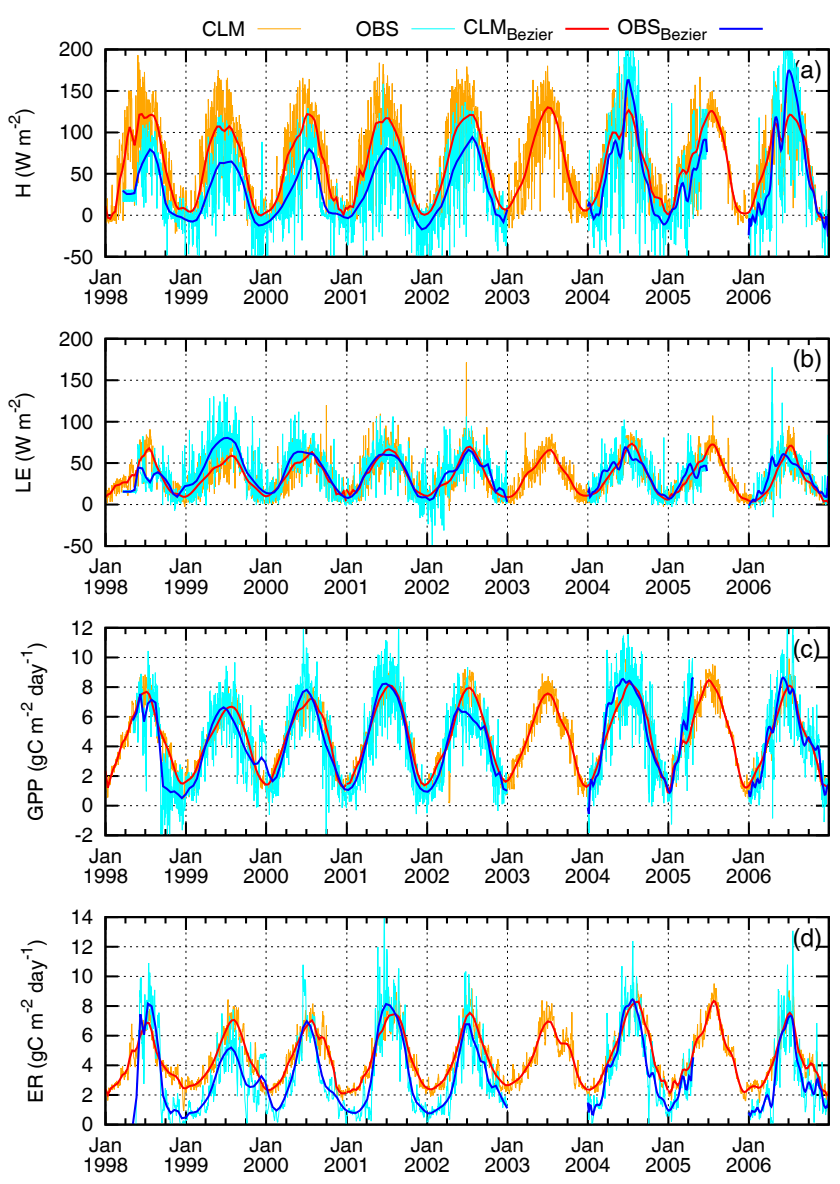

Figure 3. Modeled sensible heat flux (a), latent heat flux (b), gross primary production (c), and ecosystem respiration (d) vs. site observations. Orange and red (cyan and blue) lines correspond to modeled (observed) values. For a clearer visualization, the daily averages (thin lines) were smoothed with a Bézier algorithm (thick lines).

ter values, the modeled evapotranspiration was significantly overestimated, with summer values exceeding observations by almost $100 \%$ (Fig. A2a).

In 1998-2003 the model overestimated $H$ $\left(\mathrm{MBE} \approx 32 \mathrm{~W} \mathrm{~m}^{-2}, \mathrm{RMSE} \approx 40 \mathrm{~W} \mathrm{~m}^{-2}\right)$, while in 2004 2006 the modeled values were closer to observations $\left(\mathrm{MBE} \approx 10 \mathrm{~W} \mathrm{~m}^{-2}, \mathrm{RMSE} \approx 36 \mathrm{~W} \mathrm{~m}^{-2}\right)$. The modeled $H$ values did not present significant interannual variability in 1998-2006; however, the observations showed significantly smaller fluxes in 1998-2003 than in 2004-2006. Such changes in the magnitude of $H$ were reported as a potential data issue in the Wind River site documentation available in the AmeriFlux repository.

The overall mean EBR calculated from site observations was 0.88 (see Sect. 2.3 for calculation approach). The energy balance closure for years 2004 and 2006 was high (mean $\mathrm{EBR}=1.01$ and 1.09 , respectively). The model bias of $H$ and LE was relatively small in those years (Fig. 3a, b). In 
the years 1998, 2000, and 2001, mean EBR was significantly lower $(0.63,0.69$, and 0.76 , respectively). Modeled $H$ presented a relatively large positive bias in those years (Fig. 3a). As discussed above, the observed $H$ values in 1998-2003 were significantly smaller than in 2004-2006, while the LE observations showed approximately the same pattern over the years. The low EBR for the years 1998, 2000, and 2001 supports the remark included in the AmeriFlux documentation regarding a potential data issue with $H$ and suggests that the observed values were biased low in 1998-2003. Mean EBR in 1999 was relatively high (0.92), in which the reduced $H$ values (Fig. 3a) were compensated for by larger LE values (Fig. 3b). In that year, modeled $H$ (LE) had a positive (negative) bias in respect to the observations.

Modeled GPP resembled observed values, with small differences $\left(\mathrm{MBE} \approx 0.23 \mathrm{~g} \mathrm{C} \mathrm{m}^{-2} \mathrm{day}^{-1}\right.$, $\mathrm{RMSE} \approx 1.60 \mathrm{~g} \mathrm{C} \mathrm{m}^{-2} \mathrm{day}^{-1}$ ). Modeled ER exhibited closer correspondence with measurements during the spring and summer months in general $\left(\mathrm{MBE} \approx 0.82 \mathrm{~g} \mathrm{C} \mathrm{m}^{-2} \mathrm{day}^{-1}\right.$, $\mathrm{RMSE} \approx 1.85 \mathrm{~g} \mathrm{C} \mathrm{m}^{-2} \mathrm{day}^{-1}$ ), with summer peaks especially close to measured values. In the colder months, modeled ER was significantly overestimated $\left(\mathrm{MBE} \approx 1.46 \mathrm{~g} \mathrm{C} \mathrm{m}^{-2} \mathrm{day}^{-1}\right.$, $\mathrm{RMSE} \approx 1.77 \mathrm{~g} \mathrm{C} \mathrm{m}^{-2} \mathrm{day}^{-1}$ ).

Despite the significant improvement in the seasonal behavior of ER after the $Q_{10}$ adjustments discussed in Appendix A6, the results indicate that further adjustments also including the base rate of maintenance respiration and the base decomposition rates for each litter and SOM pool within CLM would be necessary to better simulate the observed ER at Wind River. The results suggest that lower base rates and higher $Q_{10}$ values would improve the simulations at the site.

\subsection{Isotopic signatures of GPP and ER}

\subsubsection{Diurnal cycle}

Modeled $\delta^{13} \mathrm{C}_{\mathrm{GPP}}$ exhibited a well-defined diurnal cycle (Fig. 4), with minimum values in the early morning and late afternoon and a peak value typically in midafternoon, reflecting diurnal changes in the simulated iWUE (see Eqs. 10 and 12). Modeled $\delta^{13} \mathrm{C}$ values of the heterotrophic component of ecosystem respiration (HR) were approximately constant, with $\mathrm{a} \approx 0.2 \%$ o change over the entire period of study (1998-2006). Conversely, modeled $\delta^{13} \mathrm{C}$ values of the autotrophic component (AR) were found to be virtually equal to modeled $\delta^{13} \mathrm{C}_{\mathrm{GPP}}$ values during daytime. At nighttime, modeled $\delta^{13} \mathrm{C}_{\mathrm{AR}}$ was found to change abruptly towards values closer to modeled $\delta^{13} \mathrm{C}_{\mathrm{HR}}$. Because AR was the major component of the total ecosystem respiration $(\mathrm{ER}=\mathrm{AR}+\mathrm{HR}$; see Fig. 4a), modeled $\delta^{13} C_{\mathrm{ER}}$ exhibited a similar behavior compared to modeled $\delta^{13} \mathrm{C}_{\mathrm{AR}}$ (Fig. $4 \mathrm{~b}$ ).

In CLM, newly assimilated carbon is first allocated to meet the total maintenance respiration demand of live plant tissues (top priority). When this demand exceeds the supply
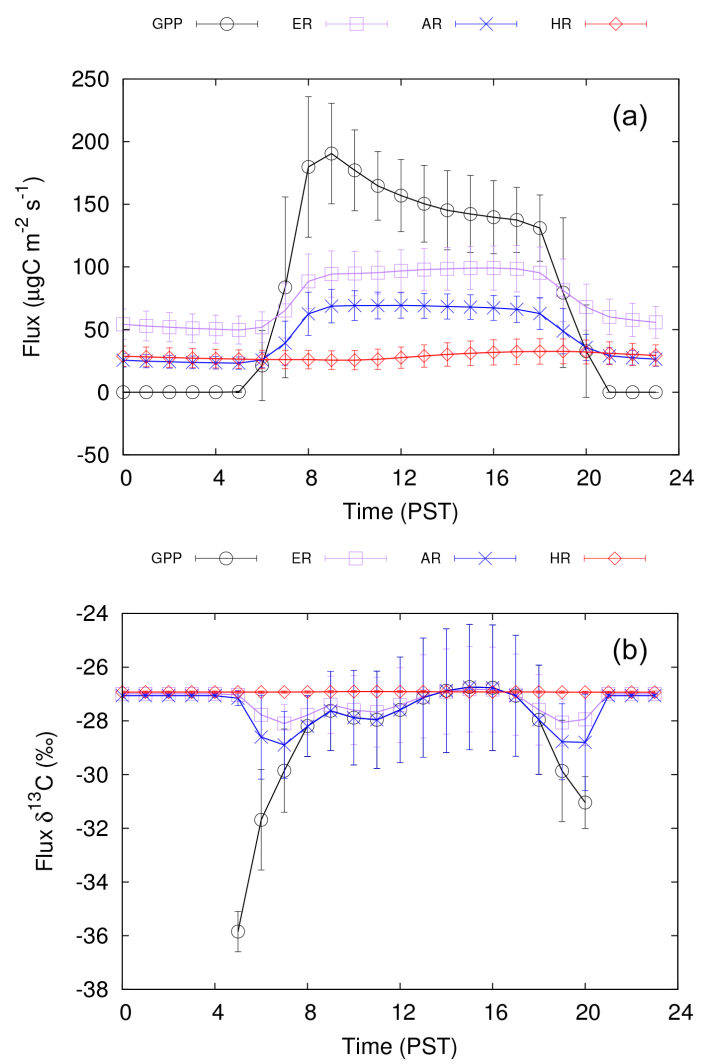

Figure 4. Mean diurnal cycle of modeled carbon fluxes (a) and their respective carbon isotope ratios (b) for the summer months (JuneSeptember) of the years 1998-2006. Fluxes include gross primary production (black circles), ecosystem respiration (purple squares), autotrophic respiration (blue crosses), and heterotrophic respiration (red diamonds). Bars correspond to $\pm 1 \mathrm{SD}$.

of carbon via photosynthesis (e.g., during nocturnal periods, wintertime, stress periods), carbon is drawn from a storage pool (excess maintenance respiration pool; $\mathrm{CS}_{\mathrm{xs}}$ ), which is allowed to run a deficit state. The reason CLM allows this deficit state is to avoid the requirement of knowing the size of the total storage pool available to plants and thus the possibility of vegetation dying in a given location if the storage pool is depleted. When negative, $\mathrm{CS}_{\mathrm{xs}}$ is gradually replenished with newly assimilated carbon at a potential rate of $-\mathrm{CS}_{\mathrm{xs}} / \tau_{\mathrm{xs}}$, where $\tau_{\mathrm{xs}}$ is a time constant (set to 30 days in CLM). The carbon allocation flux to replenish $\mathrm{CS}_{\mathrm{xs}}$ receives second priority in the model, while the carbon allocation fluxes to support plant growth have third priority. Given this allocation structure, $\delta^{13} \mathrm{C}_{\mathrm{AR}}$ will follow $\delta^{13} \mathrm{C}_{\mathrm{GPP}}$ during daytime (assuming GPP is enough to meet the maintenance respiration demand) and the $\delta^{13} \mathrm{C}$ of the "excess maintenance respiration flux" (XSMR) during nighttime. CLM does not calculate the isotopic signature of XSMR from $\mathrm{CS}_{\mathrm{xs}}$, but from bulk vegetation tissues (total vegetation carbon, TOTVEGC). This is done because $\mathrm{CS}_{\mathrm{xs}}$ is not a physical quantity but a construct of CLM. Note that XSMR borrows 
carbon from the $\mathrm{CS}_{\mathrm{xs}}$ pool, which is allowed to run a deficit state. This debt is paid in the future with the replenishment of the $\mathrm{CS}_{\mathrm{xs}}$ pool with newly assimilated carbon. This construct makes the $\delta^{13} \mathrm{C}$ of $\mathrm{CS}_{\mathrm{xs}}$ nonphysical; therefore, the approximation that $\delta^{13} \mathrm{C}_{\mathrm{XSMR}}=\delta^{13} \mathrm{C}_{\mathrm{TOTVEGC}}$ is more physically realistic. This approximation makes the nocturnal $\delta^{13} \mathrm{C}_{\mathrm{AR}}$ follow $\delta^{13} \mathrm{C}_{\text {TOTVEGC }}$, explaining the low sensitivity of the nocturnal $\delta^{13} \mathrm{C}_{\mathrm{AR}}$ to recent ${ }^{13} \mathrm{C}$ discrimination in the results shown in Fig. $4 \mathrm{~b}$.

Autotrophic respiration at Wind River is likely fueled by a mixture of stored and recently fixed carbon, as indicated by ${ }^{14} \mathrm{C}$ measurements from root respiration (RR) at the site (Taylor et al., 2015). This process cannot be appropriately modeled by CLM with the current carbon allocation scheme, impacting the simulation of $\delta^{13} \mathrm{C}_{\mathrm{ER}}$. An explicit representation of carbohydrate storage pools within CLM to support the maintenance respiration demand would improve the simulation of $\delta^{13} \mathrm{C}_{\mathrm{ER}}$. The need for a better representation of carbohydrate storage pools within CLM was also highlighted by the ${ }^{13} \mathrm{CO}_{2}$-labeling study conducted by Mao et al. (2016).

It is important to highlight that, unlike models such as $\mathrm{SiB}$ (Sellers et al., 1996; Vidale and Stöckli, 2005), CLM does not have a prognostic canopy airspace where $\delta^{13} \mathrm{CO}_{2}$ is impacted by photosynthetic and respiratory fluxes; thus, the simulation of $\delta^{13} \mathrm{C}_{\mathrm{GPP}}$ is not affected by the limitations in the simulation of $\delta^{13} \mathrm{C}_{\mathrm{ER}}$ described above.

\subsubsection{Seasonal cycle}

Modeled $\delta^{13} \mathrm{C}_{\mathrm{GPP}}$ exhibited a well-defined seasonal pattern, peaking during the summer as a result of a decrease in the photosynthetic ${ }^{13} \mathrm{C}$ discrimination associated with higher iWUE values (Fig. 5; see also Eqs. 10 and 12). The summer peak in iWUE was linked to changes in stomatal conductance in response to increased VPD and reduced SWC during the dry summer season.

On a monthly scale, roughly indicated by the smoothed curve in Fig. 5, the modeled $\delta^{13} \mathrm{C}_{\mathrm{GPP}}$ values presented a similar seasonal pattern in comparison with the $\delta^{13} \mathrm{C}_{\mathrm{ER}}$ observations by Lai et al. (2005) at the site. Differences between $\delta^{13} \mathrm{C}_{\mathrm{GPP}}$ and $\delta^{13} \mathrm{C}_{\mathrm{ER}}$ are obviously expected, as $\delta^{13} \mathrm{C}_{\mathrm{ER}}$ depends on the contribution of recently assimilated carbon to AR, the AR:ER ratio, and also post-photosynthetic fractionation (Bowling et al., 2008; Brüggemann et al., 2011). The seasonal pattern in the observed $\delta^{13} \mathrm{C}_{\mathrm{ER}}$ (Fig. 5) could be partially attributed to an eventual spring-to-summer decrease in the AR: ER ratio (assuming $\delta{ }^{13} \mathrm{C}_{\mathrm{HR}}>\delta \delta^{13} \mathrm{C}_{\mathrm{AR}}$ ). ${ }^{14} \mathrm{C}$ measurements from belowground respiration components at Wind River reported by Taylor et al. (2015) do indicate a spring-to-summer decrease in the contribution of RR towards total soil respiration $(\mathrm{SR}=\mathrm{RR}+\mathrm{HR})$. The similarity of the seasonal patterns of observed $\delta^{13} \mathrm{C}_{\mathrm{ER}}$ and modeled $\delta^{13} \mathrm{C}_{\mathrm{GPP}}$ suggests that stomatal response to water stress could also be driving the seasonal pattern in the observed $\delta^{13} \mathrm{C}_{\mathrm{ER}}$ at the site. The broader implication is that $\delta^{13} \mathrm{C}_{\mathrm{ER}}$, which can be

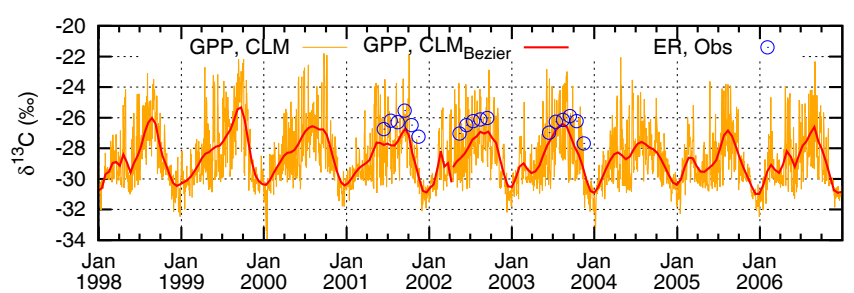

Figure 5. Modeled $\delta^{13} \mathrm{C}$ of gross primary production (lines) and observed $\delta^{13} \mathrm{C}$ of ecosystem respiration (circles). Thin orange line corresponds to daily averages using 10:00-16:00 PST data only. For a clearer visualization, this curve was smoothed with a Bézier algorithm (thick red line). Blue circles correspond to site observations (monthly averages) reported by Lai et al. (2005).

more easily measured than $\delta^{13} \mathrm{C}_{\mathrm{GPP}}$, can be reasonably used as a surrogate to indicate forest response to water stress at Wind River.

Due to the limitations in the carbon allocation scheme used in CLM (Sect. 3.3.1), the simulated $\delta^{13} \mathrm{C}_{\mathrm{ER}}$ values were found to be inconsistent with the site observations, with nocturnal values approximately constant throughout the entire period of study (1998-2006), exhibiting little sensitivity to recent photosynthetic ${ }^{13} \mathrm{C}$ discrimination. Diurnal values, however, were found to be strongly correlated with $\delta^{13} \mathrm{C}_{\mathrm{GPP}}$, given the fact that in CLM current photosynthate directly fuels AR (results not shown).

The adjustment of the stomatal conductance parameters $m_{\mathrm{bb}}$ and $b_{\mathrm{bb}}$ to improve the simulation of evapotranspiration (Sect. 2.6, Table 1 and Appendix A9) led to a significant change in the simulation of $\delta^{13} \mathrm{C}_{\mathrm{GPP}}$. When the default parameter values were used, modeled $\delta^{13} \mathrm{C}_{\mathrm{GPP}}$ was generally $2-3 \%$ o lower due to higher photosynthetic ${ }^{13} \mathrm{C}$ discrimination (Fig. A2b), also presenting a considerable reduction in the amplitude of the seasonal cycle. The difference between modeled $\delta^{13} \mathrm{C}_{\mathrm{GPP}}$ and observed $\delta^{13} \mathrm{C}_{\mathrm{ER}}$ was significantly larger. As discussed in Sect. 3.1, site observations of leaf and SOM $\delta{ }^{13} \mathrm{C}$ support the notion that the default stomatal conductance parameters are inadequate at Wind River, resulting in excessive photosynthetic ${ }^{13} \mathrm{C}$ discrimination.

\subsection{Ecosystem response to water stress}

Overall, CLM was able to reasonably capture the observed interannual variability in GPP at the study site (Fig. 3c). The behavior of observed GPP in 2002 and 2006 stands out, showing an early-season peak followed by a quick reduction, suggesting strong water stress in those years, especially in 2002. Among the years studied here, 2002 and 2006 had the lowest summer precipitation. Spring precipitation was also low in 2006 but normal in 2002. Observed canopy conductance during the spring and summer of 2006 was smaller than in 2002, but a stronger attenuation of GPP was observed in 2002, suggesting that water stress was not the main reason for the attenuated GPP values in 2002. CLM was able to simu- 


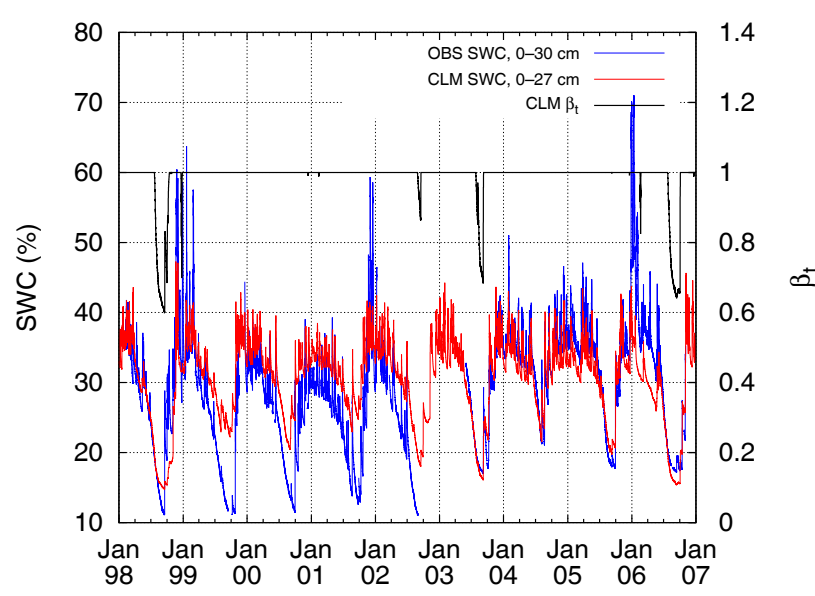

Figure 6. Hourly soil water content and CLM's soil moisture stress parameter, $\beta_{t}$ (black line). Observed SWC (blue line) corresponds to the integrated value for the top $30 \mathrm{~cm}$ of soil, while modeled SWC (red line) corresponds to the integrated value for the top five soil layers in CLM $(0-27 \mathrm{~cm})$. At Wind River, SWC at permanent wilting point and at field capacity is 14 and $30 \%$, respectively (Wharton et al., 2009).

late the observed GPP behavior in 2006 but not in 2002. The reason for the model-data mismatch in the spring-summer of 2002 is currently unclear. Despite the fact that meteorological forcing data from 1998 to 2006 were continuously cycled throughout the transient run (1850-2006), meaning that the impact of any slow secular change in the forcing data was not captured in the simulation, the simulated GPP still compared reasonably well against observations.

Throughout the simulation period (1998-2006), CLM predicted a few periods when the ecosystem was under the influence of soil moisture stress (Fig. 6). As indicated by the $\beta_{t}$ parameter (Eq. 3), which varies from 0 (maximum soil moisture stress) to 1 (no soil moisture stress) (see Sect. 2.1), those periods included the summers of 1998, 2006, 2003, and 2002, in decreasing order of stress intensity. The departures from $\beta_{t}=1$ typically occurred when modeled SWC (top five soil layers, $0-27 \mathrm{~cm}$ ) decreased below $\approx 20 \%$. Note that, at Wind River, SWC at permanent wilting point and at field capacity is 14 and $30 \%$, respectively (Wharton et al., 2009).

With the adjustment of soil hydraulic parameters (Appendix A7), CLM was able to adequately simulate SWC throughout most of the years within the study period (Fig. 6), especially during the summer months, with an overall summer MBE of $3.24 \%$. However, the simulated SWC significantly departed from observations in 1999-2002. CLM, which was driven by observed precipitation at the site, indicated higher SWC than observations in 1999-2002, particularly during the summer months, with a summer MBE of $8.05 \%$. For the remaining years, summer MBE was $-0.27 \%$. The SWC observations starting on the second year
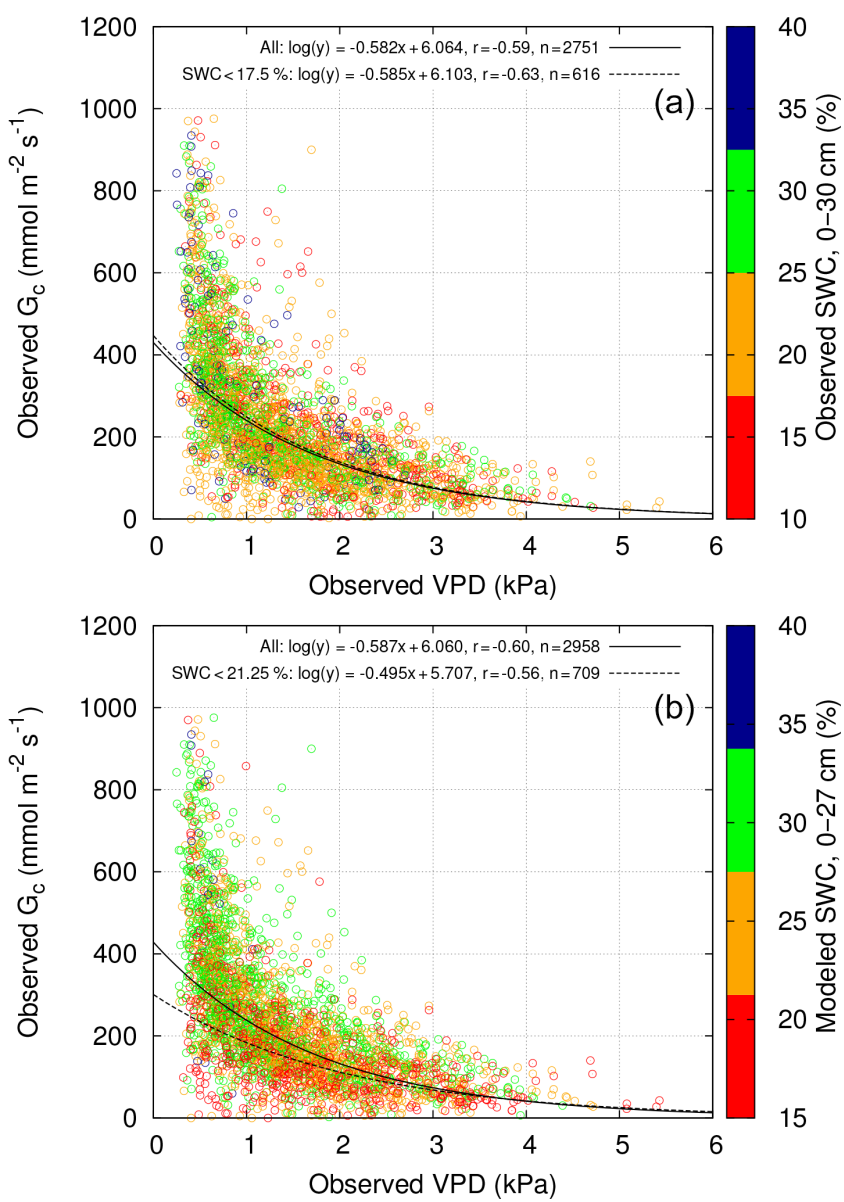

Figure 7. Hourly observed canopy conductance vs. observed VPD for the summer months (June-September) of the years 1999-2006, restricted to 10:00-16:00 PST (additional restrictions were imposed to the calculation of $G_{\mathcal{C}}$; see Sect. 2.7). The years 1998 and 2005 were not included due to missing data. Data points were segregated according to observed SWC in panel (a) and according to modeled SWC in panel (b) (see Fig. 6). Lines correspond to the linear regression between $\log G_{\mathrm{c}}$ and VPD using all data points (solid lines) and using only points within the lowest SWC bin (red circles, dashed lines).

of the site records (1999) up to the data gap in 2002 presented a different pattern in comparison with the remaining years, showing an apparent negative offset of near $10 \%$. It is likely that the apparent shift in the time series of observed SWC was instrument-related. In 1999-2002, soil moisture monitoring at the site consisted of two, two-pronged timedomain reflectometer (TDR) probes instead of six, threepronged TDR probes, likely resulting in less-accurate data collection.

Observed canopy conductance was found to be strongly dependent on VPD, following a decreasing exponential relationship (Fig. 7). In order to investigate the additional dependence on soil moisture stress, the data points were divided into four bins according to the observed values of 
SWC (Fig. 7a). The linear regression fit between $\log G_{\mathrm{c}}$ and VPD for the points corresponding to the lowest SWC bin (SWC $<17.5 \%, \approx 22 \%$ of all data points) was virtually the same as the linear regression considering all data points. If the forest were under soil moisture stress at those low SWC levels, the former regression curve with data points from the lowest SWC bin would be expected to be found below the latter. Instead, the SWC $<17.5 \%$ regression curve was very similar - even slightly above the regression curve using all data points.

The lack of sensitivity of observed $G_{\mathrm{c}}$ to observed SWC (Fig. 7a) was likely associated with a negative bias in SWC in 1999-2002. Observed $G_{\mathrm{c}}$ was found to respond to modeled SWC (driven by observed precipitation) (Fig. 7b). As discussed above, the observed SWC values in 1999-2002 were suspected to have a negative bias, i.e., drier than reality. $G_{\mathrm{c}}$ values in Fig. 7a corresponding to the summer of 1999-2002 were tagged as belonging to the lowest SWC bin, but in reality, they could be associated with wetter, non-moisture stress conditions. Assuming that CLM's summer simulated SWC (driven by observed precipitation) was not as biased as the observed SWC might be, we instead used the modeled SWC values to probe the $G_{\mathrm{c}}$ vs. VPD relationship under different SWC regimes in Fig. 7b. Interestingly, with this approach, a distinct pattern emerged for the data points within the lowest SWC bin. The regression curve considering all data points was $\log G_{\mathrm{c}}=-0.59 \mathrm{VPD}+6.06(r=-0.60)$ and when considering only the data points from the lowest bin (modeled SWC $<21.25 \%, \approx 24 \%$ of all points), the regression curve was $\log G_{\mathrm{c}}=-0.50 \mathrm{VPD}+5.71(r=-0.56)$. The latter regression curve corresponded to reasonably lower $G_{\mathrm{c}}$ values, especially at low VPD levels, which is compatible with a moisture stress scenario. The result supports the suspicion of a negative bias in the observed SWC data in 1999-2002.

Similar to observations, modeled canopy conductance was also found to be strongly dependent on VPD (Fig. 8). This is expected given the Ball-Berry stomatal conductance model used in CLM (Eq. 2). The Ball-Berry model has a direct dependence on leaf relative humidity (leaf RH), not leaf VPD, but these variables are strongly correlated. The correlation between modeled $G_{\mathrm{c}}$ and RH was found to be slightly higher than between modeled $G_{\mathrm{c}}$ and VPD, while observed $G_{\mathrm{c}}$ correlated slightly better with VPD than RH (results not shown). The results indicate that a direct dependence on leaf VPD, rather than leaf RH, in CLM's stomatal conductance model would lead to a more accurate representation of stomatal functioning at Wind River, but overall, for the period analyzed in the present study, such improvement is expected to be small. The general dependence of modeled canopy conductance on VPD was very similar in comparison with observations, as indicated by the linear regression curve between $\log G_{\mathrm{c}}$ and VPD in Fig. 8 using all data points $\left(\log G_{\mathrm{c}}=\right.$ $-0.59 \mathrm{VPD}+6.04$; compare with $\log G_{\mathrm{c}}=-0.59 \mathrm{VPD}+6.06$ in Fig. 7b). The correlation between observed $\log G_{\mathrm{c}}$ and
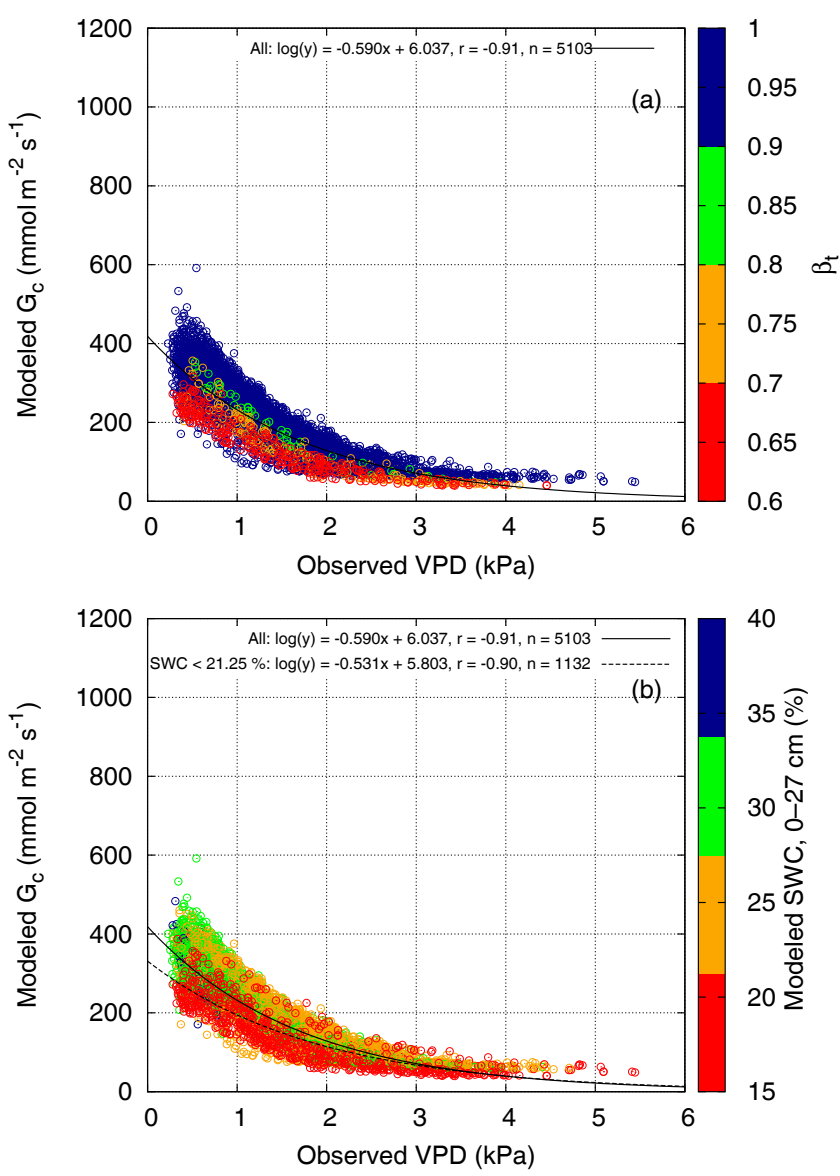

Figure 8. Hourly modeled canopy conductance vs. observed VPD for the summer months (June-September) of the years 1999-2006, restricted to 10:00-16:00 PST (additional restrictions were imposed to the calculation of $G_{\mathrm{c}}$; see Sect. 2.7). Note that observed air temperature and relative humidity were used to drive CLM. The years 1998 and 2005 were not included for consistency with Fig. 7. Data points were segregated according to the soil moisture stress parameter $\beta_{t}$ in panel (a) and according to modeled SWC in panel (b) (see Fig. 6). Lines correspond to the linear regression between $\log G_{\mathrm{c}}$ and VPD using all data points (solid lines) and using only points within the lowest SWC bin (red circles, dashed line).

VPD, however, was lower than for the model results $(r=$ -0.60 and $r=-0.91$, respectively).

The impact of soil moisture stress on $G_{\mathrm{c}}$ was reasonably captured in CLM (Fig. 8b; cf. Fig. 7b). The impact of soil moisture stress on modeled $G_{\mathrm{c}}$ is clearly visible in Fig. 8a, in which the data points were binned according to $\beta_{t}$. With increasing soil moisture stress (decreasing $\beta_{t}$ values), the modeled $G_{\mathrm{c}}$ values still maintained a strong dependence on VPD, but were shifted downward, particularly at low VPD levels. In order to allow a more direct comparison against Fig. $7 b$, the data points were binned according to modeled SWC in Fig. 8b. The points in the lowest SWC bin $(\mathrm{SWC}<21.25 \%, \approx 22 \%$ of all points $)$ 
roughly corresponded to the periods under soil moisture stress $\left(\beta_{t}<1\right)$. The regression curve for the SWC $<21.25 \%$ group lay reasonably below the regression curve considering all data points $\left(\log G_{\mathrm{c}}=-0.53 \mathrm{VPD}+5.80, r=-0.90\right.$, and $\log G_{\mathrm{c}}=-0.59 \mathrm{VPD}+6.04, r=-0.91$, respectively). The regression curves associated with $\mathrm{SWC}<21.25 \%$ were similar for the observed and modeled results (Figs. $7 \mathrm{~b}$ and $8 \mathrm{~b}$ ), indicating that CLM could reasonably simulate soil moisture stress at Wind River, although with a small underestimation (i.e., a small overestimation of $G_{\mathrm{c}}$; note the $G_{\mathrm{c}}$ intercepts at 301 and $331 \mathrm{mmol} \mathrm{m}^{-2} \mathrm{~s}^{-1}$ in Figs. $7 \mathrm{~b}$ and $8 \mathrm{~b}$, respectively). It is important to point out, however, that modeled SWC was used to segregate the observations in Fig. $7 \mathrm{~b}$ due to the potential bias in the SWC observations discussed above.

Modeled $\delta^{13} \mathrm{C}_{\mathrm{GPP}}$ and $G_{\mathrm{c}}$ values were highly correlated $(r=-0.88, p<0.001$; Fig. $9 \mathrm{~b})$. Modeled $G_{\mathrm{c}}$ generally decreased into the summer season, leading to an increase in water use efficiency and a decrease in photosynthetic ${ }^{13} \mathrm{C}$ discrimination, resulting in higher $\delta^{13} \mathrm{C}_{\mathrm{GPP}}$ values. Observed $\delta^{13} \mathrm{C}_{\mathrm{ER}}$ was found to have a low negative correlation with observed $G_{\mathrm{c}}$, but it was not statistically significant $(r=-0.27$, $p=0.396$; Fig. 9a). The low correlation was likely a result of $\delta^{13} \mathrm{C}_{\mathrm{ER}}$ reflecting constraints of prior environmental drivers in comparison with the more rapid response of $G_{\mathrm{c}}$ to more recent environmental drivers. Another possible explanation is that the monthly $\delta^{13} \mathrm{C}_{\mathrm{ER}}$ values in Fig. 9a were obtained by averaging up to four discrete weekly observations (see Sect. 2.4), in contrast with the calculation of monthly $G_{\mathrm{c}}$, which used daytime values for each day of the month. It is important to mention that the observed $\delta^{13} \mathrm{C}_{\mathrm{ER}}$ values show a clear seasonal pattern (Fig. 5), with values peaking during summer likely in response to changes in $g_{\mathrm{s}}$ and iWUE associated with increasing water stress (see discussion in Sect. 3.3.2), but the present results indicate a lag in this response.

\section{Discussion}

\subsection{Ecosystem response to water stress}

We found that the major cause of water stress leading to stomatal response at Wind River during summer was the elevated VPD, and not the reduced soil moisture (Sect. 3.4). Observed canopy conductance values at the site strongly decreased at moderate VPD levels, regardless of soil moisture conditions (Fig. 7b). The high sensitivity of stomatal response to changes in VPD was also shown and discussed in Wharton et al. (2009). As pointed out in their study, "even under moderate VPD levels, foliage at the tops of tall evergreen conifer trees often reach near critical values for cavitation due to a long path distance between the water table and the hydraulic capacity of the xylem, and as a result shut their stomata frequently (Ryan and Yoder 1997)". They also point out that soil moisture depletion is usually not limiting
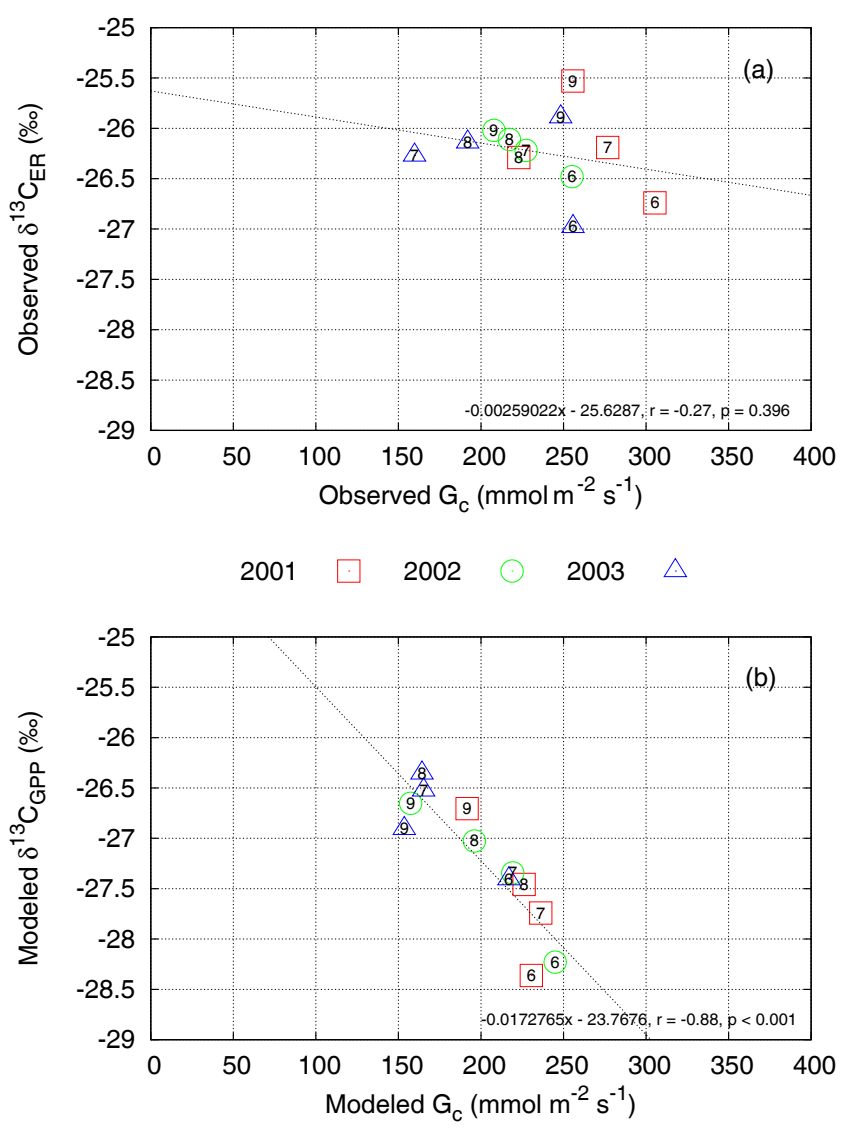

$2001 \square 2002 \bigcirc 2003 \triangle$

Figure 9. Observed $\delta^{13} \mathrm{C}$ of ecosystem respiration vs. observed canopy conductance (a) and modeled $\delta^{13} \mathrm{C}$ of gross primary production vs. modeled canopy conductance (b) for the summer months of 2001-2003. Except for the observed $\delta^{13} \mathrm{C}_{\mathrm{ER}}$, data points correspond to monthly averages of daytime (10:00-16:00 PST) data (additional restrictions were imposed to the calculation of $G_{\mathrm{c}}$; see Sect. 2.7). Observed $\delta^{13} \mathrm{C}_{\mathrm{ER}}$ corresponds to the monthly averages reported by Lai et al. (2005). Numbers at the center of each point indicate the month.

at the site because the mature trees are capable of tapping water from deeper soil layers. This is generally consistent with our findings (Sect. 3.4); however, we also found that stomatal conductance responded to soil moisture stress during periods of more severe SWC depletion and low VPD (Fig. 7b).

Overall, CLM was able to simulate the observed response of canopy conductance to VPD and SWC, reasonably capturing the impact of water stress on ecosystem functioning (Fig. 8). Similarly to observations, VPD exerted a strong limitation on modeled $G_{\mathrm{c}}$, while SWC was usually not limiting. Note that $\beta_{t}$ was equal to 1 (no soil moisture stress) throughout most of the period of study (Fig. 6), in alignment with the explanation by Wharton et al. (2009) that the mature trees at the site are capable of accessing water from deeper soil layers. Note also that the default NETT PFT root distribution in 
CLM was shifted towards deeper soil layers (Appendix A8), aiming to improve the simulation of $\beta_{t}$. Despite the good overall model-data agreement $\left(G_{\mathrm{c}}\right.$ dependency on VPD and SWC) after calibration, the results indicate a small underestimation of soil moisture stress in CLM, as discussed in Sect. 3.4. Calibration of the parameters controlling the plant wilting factor (Eq. 5) and additional calibration of the root distribution parameters could improve the results but are out of scope here.

An obvious but important point that must be highlighted is that in order to adequately simulate soil moisture stress, CLM must first adequately simulate SWC. Even when the model is driven by observed precipitation data (the case of the present study), this task is not trivial. As discussed in Appendix A7, CLM's hydrology sub-model performed poorly at Wind River when the default soil hydraulic parameters were used, leading to a strong dry bias in SWC. The original parameters used in the previous version of CLM (version 4.0) were found to perform much better at the site, likely due to a reduction of subsurface runoff and consequent increase in water retention in the soil column. As the default parameter values are intended for global simulations, it is natural to expect site-to-site variation in model performance (see Sect. 4.2). Raczka et al. (2016), for instance, did not find issues with the default soil hydraulic parameters in their CLM4.5 simulation at the Niwot Ridge AmeriFlux site. This difference in impact between the sites may have resulted from unique soil properties or differences in precipitation and evaporative demand between the sites during the summer.

As pointed out in Sect. 3.4, the results of the present study indicate that a direct dependence on leaf VPD in CLM's stomatal conductance model, rather than leaf RH, would lead to a more accurate representation of stomatal functioning at Wind River, but overall, for the period analyzed in the present study, such improvement is expected to be small. It is important to emphasize that this expectation refers to the results presented here only. In the case of model predictions under future climate scenarios, in which atmospheric VPD is predicted to change while RH stays the same (as discussed in Sato et al., 2015), a direct dependence on leaf VPD in the stomatal conductance model becomes critical. The next CLM release (version 5) is expected to replace the BallBerry model with the Medlyn model (Medlyn et al., 2011), which directly depends on leaf VPD. This modification is expected to be more relevant for climate change simulations. Note that the present analysis is based on a hindcast simulation using a stable climate.

\subsection{Calibration of CLM}

Substantial calibration of model parameters was necessary to simulate the observed energy and carbon dynamics at Wind River, an old-growth ( $\sim 500$ years old) coniferous forest site dominated by Douglas fir and western hemlock trees and characterized by a Mediterranean climate. This is not sur- prising given that the default parameters used in CLM are intended for global simulations. Thus, model performance at particular sites is expected to vary greatly, requiring sitespecific calibration in order to adequately simulate the observations. This is also demonstrated in the studies by Raczka et al. (2016) and Mao et al. (2016). Raczka et al. (2016) investigated the performance of CLM at the Niwot Ridge AmeriFlux site, a 110-year-old subalpine coniferous forest site in Colorado, USA, consisting of lodgepole pine, Engelmann spruce, and subalpine fir, while Mao et al. (2016) evaluated CLM in a 10-year-old loblolly pine stand in Tennessee, USA. In both cases significant site-specific specification and calibration of model parameters were also necessary. Note that these sites fall into the same PFT category as Wind River (NETT PFT). Despite the significant differences between the three sites, the results presented here and in Raczka et al. (2016) and Mao et al. (2016) converge in respect to the calibration of the Ball-Berry stomatal conductance slope, $m_{\mathrm{bb}}$. It is promising that despite the range in stand age and climate conditions amongst these sites, there appears to be a consensus that reduced stomatal conductance is required across all sites. This bodes well when upscaling to regional simulations.

A reduction of $m_{\mathrm{bb}}$ from 9 (default) to 6 was necessary to simulate the observed GPP, LE, and $\delta^{13} \mathrm{C}$ values (leaf, $\mathrm{SOM})$ at Wind River. This aligns with the results by Mao et al. (2016), as they were able to simulate the observations at their Tennessee site, including biomass $\delta^{13} \mathrm{C}$ values, with an optimized $m_{\mathrm{bb}}$ of 5.6. However, as discussed in Appendix A9, the present results show that the significant reduction of $m_{\mathrm{bb}}$ from 9 to 6 may represent a tradeoff with model representation of nitrogen limitation. When using CLM's default nitrogen limitation scheme and $m_{\mathrm{bb}}$ value, Raczka et al. (2016) found significant overestimation of ${ }^{13} \mathrm{C}$ discrimination at Niwot Ridge due to excessive stomatal conductance, similar to the present study. When using an alternative nitrogen limitation scheme based on $V_{\mathrm{cmax} 25}$ downregulation, maintaining the coupling between net leaf assimilation and $g_{s}$, Raczka et al. (2016) found significant improvement in the simulations. This alternative scheme was also tested here while keeping the default $m_{\mathrm{bb}}$ value, and the results were similar compared to the model run with the default nitrogen limitation scheme and $m_{\mathrm{bb}}=6$ (Appendix A9).

The results in the present study indicate that it is possible to account for the partial coupling between net leaf assimilation and stomatal conductance in CLM through the adjustment of $m_{\mathrm{bb}}$ to achieve reasonable carbon and energy exchange behavior, including ${ }^{13} \mathrm{C}$ discrimination. This is also supported by the results in Mao et al. (2016). A more detailed evaluation of model skill in simulating ${ }^{13} \mathrm{C}$ discrimination with this approach, in comparison with the $V_{\mathrm{cmax} 25}$ downregulation approach (fully coupled CLM), would depend on high-frequency observations of $\delta^{13} \mathrm{C}_{\mathrm{GPP}}$ as in Raczka et al. (2016). These data were not available at Wind River. Note 
that ${ }^{13} \mathrm{C}$ discrimination at Wind River was inferred from $\delta^{13} \mathrm{C}$ measurements of leaves and SOM.

The results in Raczka et al. (2016), Mao et al. (2016), and the present study indicate that $m_{\mathrm{bb}}=9$ is excessive when the default nitrogen limitation implementation is used in the simulations, with the latter two studies indicating that $m_{\mathrm{bb}} \approx 6$ is a more appropriate value to simulate the site observations. This agreement at three very distinct sites is encouraging and suggests that CLM could possibly benefit from a revised $m_{\mathrm{bb}}$ value of 6 for the NETT PFT, keeping in mind that such adjustment to improve model skill would also account for structural error. At the same time, the results presented here and in Raczka et al. (2016) indicate that the default $m_{\mathrm{bb}}=9$ is reasonable for simulations when the $V_{\mathrm{cmax} 25}$ down-regulation scheme is implemented in the model, although Raczka et al. (2016) still found a small overestimation of ${ }^{13} \mathrm{C}$ discrimination at Niwot Ridge, suggesting that a smaller $m_{\mathrm{bb}}$ value would better simulate the site dynamics. It is important to point out, however, that the experimental literature indicates generally lower $m_{\mathrm{bb}}$ values for coniferous forests (see for example the surveys by Williams et al., 2004, Table 6.3, and Miner et al., 2017, Fig. 1). The SiB model (Sellers et al., 1996), for instance, uses $m_{\mathrm{bb}}=6$ for conifers and $m_{\mathrm{bb}}=9$ for other $\mathrm{C}_{3}$ plants, while CLM uses $m_{\mathrm{bb}}=9$ for all $\mathrm{C}_{3}$ plants. Further investigation of the applicability of the revised $m_{\mathrm{bb}}$ value (or the current default value while using the $V_{\text {cmax } 25}$ down-regulation scheme as in Raczka et al., 2016) at other NETT PFT sites is recommended for future studies.

\subsection{Recommendations for structural improvement within CLM}

The results of the present study demonstrate that $\delta^{13} \mathrm{C}$ observations can be used to constrain stomatal conductance and iWUE in CLM as an alternative to eddy covariance flux measurements, leveraging the recent implementation of photosynthetic ${ }^{13} \mathrm{C}$ discrimination within the model. The adjustments made on the parameters controlling stomatal conductance within the model, originally aiming to improve the simulation of evapotranspiration, were critical to simulating the observed photosynthetic ${ }^{13} \mathrm{C}$ discrimination at Wind River, inferred from $\delta^{13} \mathrm{C}$ measurements of leaves and SOM. As discussed in Sect. 4.2, these adjustments to improve model skill interacted strongly with the nitrogen limitation scheme. A possible interpretation of results from this and other recent studies is that growth limitation due to restricted nitrogen availability does not operate instantaneously upon photosynthesis (e.g., through nitrogen downscaling in the default version of CLM4.5) but is accounted for further "downstream" during the allocation of carbon.

For example, Metcalfe et al. (2017) proposed a revised model structure in which GPP is not instantaneously downregulated during photosynthesis, but the excess photosynthate, which cannot be allocated to structural pools due to insufficient nitrogen supply, is allocated to a new nonstructural carbohydrate storage pool within the model. Carbon from this pool is able to return to the atmosphere via the inclusion of a single additional respiration term within the model. This new model structure provides a solution for the issue regarding the partial coupling between net leaf assimilation and stomatal conductance. Alternatively, a foliar nitrogen model could be used to account for nitrogen limitation directly within the estimation of photosynthetic capacity (Ghimire et al., 2016), removing the requirement for nitrogen downscaling. A similar approach is planned to be included in the next release of CLM (version 5.0).

The use of $\delta^{13} \mathrm{C}_{\mathrm{ER}}$ observations as a strong constraint upon CLM is hindered by the lack of an explicit representation of carbohydrate storage pools within the model to support autotrophic respiration (Fig. 4). The results from the ${ }^{13} \mathrm{C}$ labeling study by Mao et al. (2016) also illustrate the issue and highlight the need for structural improvements in CLM's carbon allocation scheme. One implication of this issue is that it prevents a more direct use of $\delta^{13} \mathrm{C}_{\mathrm{ER}}$ observations - which are easier to obtain and more frequently available than $\delta^{13} \mathrm{C}_{\mathrm{GPP}}$ observations - for evaluation of ${ }^{13} \mathrm{C}$ discrimination in CLM. It may also limit the applicability of CLM for global atmospheric ${ }^{13} \mathrm{C}$ budget studies focusing on landocean flux partitioning (e.g., van der Velde et al., 2013), as errors in the simulation of the land isotopic disequilibrium $\left(\delta^{13} \mathrm{C}_{\mathrm{ER}}-\delta^{13} \mathrm{C}_{\mathrm{GPP}}\right.$ ) can propagate to the estimation of the land-ocean partitioning and the estimation of variability in each sink (van der Velde et al., 2014). Van der Velde et al. (2014) were able to reasonably simulate mean observed $\delta^{13} \mathrm{C}_{\mathrm{ER}}$ values for a selection of sites from the BiosphereAtmosphere Stable Isotope Network (BASIN; Pataki et al., 2003) using a modified version of the SiB-CASA model including representation of ${ }^{13} \mathrm{C}$ isotopes and modified carbon storage pools. The original SiB-CASA model (Schaefer et al., 2008) has a single storage pool representing sugars and starch, with only the sugar portion being readily available for plant growth and maintenance. The effective pool turnover rate in this configuration is $\sim 70$ days. In the modified model, sugar and starch allocation are simulated separately with two distinct pools, with prescribed turnover rates of 7 days (sugar to starch) and 63 days (starch to sugar). Van der Velde et al. (2014) found significant improvement in the simulation of $\delta^{13} \mathrm{C}_{\mathrm{ER}}$ with the new carbon allocation approach. We recommend that CLM adopt a similar carbon allocation scheme, moving away from the deficit-based accounting scheme (Sect. 3.3.1) towards an explicit representation of carbohydrate storage pools such as in the SiB-CASA model (van der Velde et al., 2014).

Another shortcoming in CLM is the fact that mesophyll conductance $\left(g_{\mathrm{m}}\right)$ is not simulated, i.e., intracellular and intercellular $\mathrm{CO}_{2}$ values are assumed to be equal. As demonstrated here and in Raczka et al. (2016) and Mao et al. (2016), CLM is able to reasonably simulate ${ }^{13} \mathrm{C}$ discrimination by either adjusting the stomatal conductance slope parameter 
or using an alternative nitrogen limitation scheme $\left(V_{\mathrm{cmax} 25}\right.$ down-regulation), but the impact of not including $g_{\mathrm{m}}$ in the simulations must be investigated. Mesophyll conductance was recently incorporated in CLM by Sun et al. (2014); however, it still has to be linked to the carbon isotope submodel. This is another area in which ${ }^{13} \mathrm{C}$ observations can be used for model evaluation and development.

\section{Conclusions}

After substantial calibration of model parameters, CLM was able to simulate energy and carbon fluxes, leaf area index, and carbon stocks at an old-growth coniferous forest (Wind River AmeriFlux site) in general agreement with site observations. Overall, the calibrated CLM was able to simulate the observed response of canopy conductance to atmospheric vapor pressure deficit and soil water content, reasonably capturing the impact of water stress on ecosystem functioning. Key model adjustments to simulating observed flux and carbon stock patterns included (1) parameters controlling the variation in specific leaf area through the forest canopy (SLA $\mathrm{S}_{0}$, $m$ ), with significant impact on GPP, (2) parameters controlling stomatal conductance $\left(m_{\mathrm{bb}}, b_{\mathrm{bb}}\right)$, with significant impact on the simulated latent heat flux and water use efficiency, and (3) soil hydraulic parameters, with impact on soil water content and on the soil moisture stress parameter, $\beta_{t}$.

The calibrated CLM was able to simulate carbon isotope ratios of leaves and soil organic matter at Wind River, in general agreement with site observations. The adjustments made on the parameters controlling stomatal conductance within the model, originally aiming to improve the simulation of evapotranspiration, were critical to simulating the observed photosynthetic ${ }^{13} \mathrm{C}$ discrimination at the site, inferred from $\delta^{13} \mathrm{C}$ measurements of leaves and soil organic matter. This demonstrates that stable carbon isotopes can serve as an alternative to eddy covariance flux measurements for constraining stomatal conductance. The simulation of nocturnal $\delta^{13} \mathrm{C}_{\mathrm{ER}}$ was found to be inconsistent with site observations, with results showing little sensitivity to recent photosynthetic ${ }^{13} \mathrm{C}$ discrimination. The inclusion of explicit carbohydrate storage pools within CLM (and removal of the current deficitbased carbon accounting system) to support the maintenance respiration demand from live plant tissues would improve the simulation of $\delta^{13} \mathrm{C}_{\mathrm{ER}}$.
We found that an optimized stomatal slope value $\left(m_{\mathrm{bb}}=\right.$ 6) was necessary at Wind River, consistent with previous CLM experiments from distinct needleleaf evergreen temperate forest sites. This suggests that this parameterization could apply to broader-scale simulations of this PFT. We also found a tradeoff between adjustment of stomatal slope and changes to the nitrogen limitation scheme. The best long-term solution may be to replace this nitrogen scheme with alternative approaches.

The hydrology submodel within CLM and its parameterization deserve special attention because the simulation of soil water content has a direct impact on $\beta_{t}$, and thus on stomatal conductance. Wind River required a unique calibration to achieve reasonable soil moisture, which was not consistent across other sites. This suggests that simulation of soil moisture in regional studies should be used with caution.

The recent inclusion of the photosynthetic ${ }^{13} \mathrm{C}$ discrimination functionality in CLM opens a new opportunity for model testing and development. The results presented here demonstrate that carbon isotopes can expose structural weaknesses in the model, such as the deficit-based accounting system in CLM's carbon allocation scheme and the partial coupling between net leaf photosynthesis and stomatal conductance caused by the nitrogen limitation scheme. $\delta^{13} \mathrm{C}$ observations provide a key constraint that may guide future CLM development.

Data availability. CLM4.5 (Oleson et al., 2013) can be obtained at http://www.cesm.ucar.edu/models/cesm1.2/. AmeriFlux data are currently available at http://ameriflux.lbl.gov (see Wharton, 19982016). Model output data presented in this paper are available upon request to the corresponding author. 


\section{Appendix A: CLM calibration}

Most of the adjustments were performed on parameters particular to the needleleaf evergreen temperate tree plant functional type in CLM. For brevity, this plant functional type is referred to as NETT PFT in the following sections.

\section{A1 Carbon allocation ratios}

By default, CLM uses a dynamic new-stem-carbon-to-newleaf-carbon allocation ratio $\left(A_{\mathrm{s}: 1}, \mathrm{gC} \mathrm{g} \mathrm{C}^{-1}\right)$ for the NETT PFT, which rises with increasing net primary production. A survey by White et al. (2000) indicates an average $A_{\mathrm{s}: 1}$ of $2.2 \pm 0.89 \mathrm{~g} \mathrm{C} \mathrm{g} \mathrm{C}^{-1}$ for needleleaf evergreen forests. Measurements reported by Hudiburg et al. (2013) for a region close to the Wind River site and characterized by forests of similar species composition vary between approximately 1 and $3.5 \mathrm{~g} \mathrm{Cg} \mathrm{C}^{-1}$ (their Fig. A1 - Mesic sites). A fixed value of $A_{\mathrm{s}: 1}=2 \mathrm{~g} \mathrm{Cg} \mathrm{C}^{-1}$ (value also used by Thornton et al., 2002 in their Biome-BGC simulations for the Wind River site) was found to improve the simulated forest biomass and was adopted in this study for the NETT PFT.

The new-fine-root-carbon-to-new-leaf-carbon allocation ratio parameter $\left(A_{\mathrm{fr}: 1}, \mathrm{gC} \mathrm{g} \mathrm{C}^{-1}\right)$ for the NETT PFT was also changed based on observations at the Wind River site reported in the AmeriFlux database, indicating $A_{\mathrm{fr}: 1}=$ $0.385 \mathrm{~g} \mathrm{C} \mathrm{g} \mathrm{C}^{-1}$ rather than the default value of $1 \mathrm{~g} \mathrm{C} \mathrm{g} \mathrm{C}^{-1}$. The change meant a significantly greater carbon investment to leaves, helping to increase the modeled GPP towards the site observations.

\section{A2 Carbon : nitrogen ratios}

Leaf litter $\mathrm{C}: \mathrm{N}$ ratio $\left(\mathrm{CN}_{\mathrm{llit}}, \mathrm{g} \mathrm{Cg} \mathrm{N}^{-1}\right)$ for the NETT PFT was adjusted based on measurements at the Wind River site (Klopatek, 2007) to $76.4 \mathrm{~g} \mathrm{Cg} \mathrm{N}^{-1}$ (mean observed value). Based on the mean observed $\mathrm{CN}_{11 \text { lit }}$ and assuming a nitrogen retranslocation efficiency of $50 \%$ (survey by Parkinson, 1983, indicates efficiencies around $50 \%$ for conifer trees and 36-69\% for Douglas fir in particular), the leaf

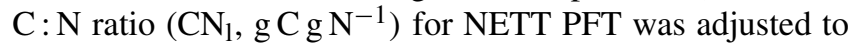
$38.2 \mathrm{~g} \mathrm{C} \mathrm{g} \mathrm{N}^{-1}$. The updated parameters differ little from the default values $\left(\mathrm{CN}_{\mathrm{llit}}=70 \mathrm{~g} \mathrm{Cg} \mathrm{N}^{-1}, \mathrm{CN}_{\mathrm{l}}=35 \mathrm{~g} \mathrm{Cg} \mathrm{N}^{-1}\right)$.

Fine-root $\mathrm{C}: \mathrm{N}$ ratio $\left(\mathrm{CN}_{\mathrm{fr}}, \mathrm{gC}^{-1}\right)$ for the NETT PFT was also adjusted based on measurements at the Wind River site (Klopatek, 2007). The value was adjusted from $42 \mathrm{~g} \mathrm{Cg} \mathrm{N}^{-1}$ (default) to $64.7 \mathrm{~g} \mathrm{Cg} \mathrm{N}^{-1}$ (mean observed value), meaning a significantly smaller nitrogen investment in fine roots resulting in more nitrogen for investment in leaves. This change helped to increase the modeled GPP towards the site observations.

\section{A3 Leaf longevity}

Measurements reported by Hudiburg et al. (2013) for a region near the Wind River site and characterized by forests of similar species composition indicate leaf longevity $\left(\tau_{1}\right)$ of 5 years. This value was adopted for the NETT PFT, replacing the default value of 3 years. This change contributed particularly to an increase in the modeled leaf area index.

\section{A4 Specific leaf area}

In CLM, specific leaf area (SLA, $\mathrm{m}^{2}$ leaf $\mathrm{g} \mathrm{C}^{-1}$ ) is assumed to be linear with canopy depth $x$ (expressed as overlying leaf area index, $\mathrm{m}^{2}$ leaf $\mathrm{m}^{-2}$ ground) (Thornton and Zimmermann, 2007):

$\operatorname{SLA}(x)=\operatorname{SL} A_{0}+m x$,

where $\mathrm{SLA}_{0}$ is the specific leaf area at the top of canopy and $m$ is a linear coefficient $\left(\mathrm{m}^{2}\right.$ ground $\mathrm{g} \mathrm{C}^{-1}$ ). Integrating this equation over the canopy, a relationship can be established in which leaf area index (LAI, $\mathrm{m}^{2} \mathrm{leaf}^{-2}$ ground) is calculated as a function of leaf carbon $\left(\mathrm{C}_{1}, \mathrm{~g} \mathrm{C} \mathrm{m}^{-2}\right.$ ground), knowing the parameters $\mathrm{SLA}_{0}$ and $m$ (Thornton and Zimmermann, 2007):

$\mathrm{LAI}=\frac{\operatorname{SL} A_{0}\left(e^{m \mathrm{C}_{1}}-1\right)}{m}$.

The default NETT PFT values in CLM for SLA $\mathrm{S}_{0}$ and $m$ are $0.01 \mathrm{~m}^{2}$ leaf $\mathrm{g} \mathrm{C}^{-1}$ and $0.00125 \mathrm{~m}^{2}$ ground $\mathrm{g} \mathrm{C}^{-1}$, respectively. These values were found to be too large for the Wind River site. Using them in Eq. (A2) with a $C_{1}$ of $941 \mathrm{~g} \mathrm{C} \mathrm{m}^{-2}$ ground (mean observation at the Wind River site reported in the AmeriFlux database) results in an LAI of $\approx 18 \mathrm{~m}^{2}$ leaf $\mathrm{m}^{-2}$ ground, instead of $\approx 9 \mathrm{~m}^{2}$ leaf $\mathrm{m}^{-2}$ ground according to the observations at the Wind River site (AmeriFlux database).

In CLM, the maximum rate of carboxylation at $25^{\circ} \mathrm{C}$ $\left(V_{\mathrm{cmax} 25}\right)$ is proportional to the area-based leaf nitrogen concentration defined as $\mathrm{N}_{\mathrm{a}}=1 /\left(\mathrm{CN}_{1} \mathrm{SLA}_{0}\right)$, i.e., $V_{\mathrm{cmax} 25} \propto$ $1 / \mathrm{SLA}_{0}$. Using the default NETT PFT values for SLA $\mathrm{SL}_{0}$ and $m$ led to the development of large and thin leaves with reduced $\mathrm{N}_{\mathrm{a}}$ and $V_{\mathrm{cmax} 25}$, resulting in excessive LAI and significant down-regulation of GPP. Smaller SLA $\mathrm{S}_{0}$ values were attempted (manual trial and error), with $m$ values constrained by Eq. (A2), the SLA 0 value, and the site observations of LAI and $\mathrm{C}_{1}$ mentioned above, aiming to minimize model errors in the simulation of GPP and LAI. SLA $A_{0}=0.006 \mathrm{~m}^{2}$ leaf $\mathrm{g} \mathrm{C}^{-1}$ and $m=0.000985 \mathrm{~m}^{2}$ ground $\mathrm{g} \mathrm{C}^{-1}$ were found to significantly improve the simulations and were adopted instead of the default values. Measurements reported by Woodruff et al. (2004) indicate that the ratio of leaf dry mass to leaf area reaches $263 \mathrm{~g} \mathrm{~m}^{-2}$ leaf near the canopy top at Wind River (their Fig. 6). Assuming that the mass of carbon is $50 \%$ of the dry mass, the observed value corresponds to $131.5 \mathrm{~g} \mathrm{C} \mathrm{m}^{-2}$ leaf, i.e., an $\mathrm{SLA}_{0}$ value of $0.0076 \mathrm{~m}^{2}$ leaf $\mathrm{g} \mathrm{C}^{-1}$, indicating that the optimized $\mathrm{SLA}_{0}$ value moved in the right direction from the default NETT PFT value $\left(0.0100\right.$ down to $0.0060 \mathrm{~m}^{2}$ leaf $\left.\mathrm{g} \mathrm{C}^{-1}\right)$, but ended up slightly lower than the observed value. 

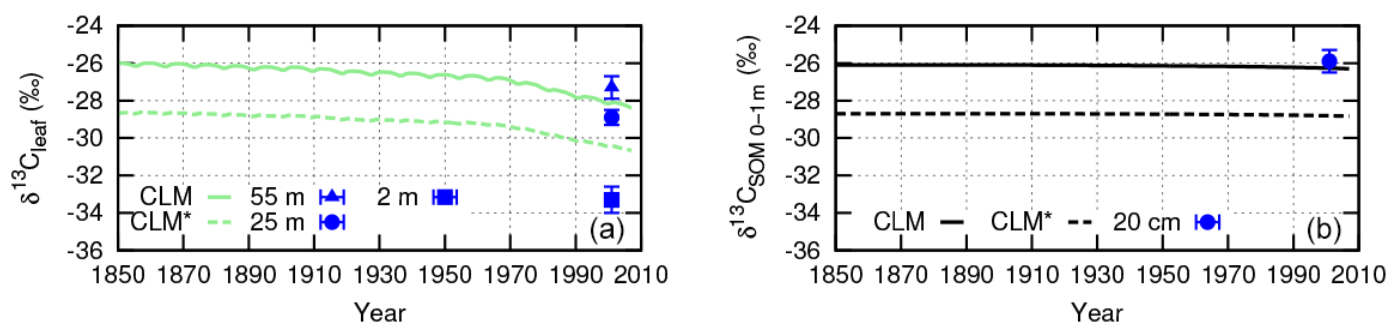

Figure A1. Modeled $\delta^{13} \mathrm{C}$ of leaf (a) and soil organic matter (b), calculated from annual averages of the respective ${ }^{13} \mathrm{C}$ and ${ }^{12} \mathrm{C}$ pools during the transient run (lines). Results from two model configurations are presented: CLM (calibrated model, solid lines) and CLM* (calibrated model using the default stomatal conductance parameters ( $m_{\mathrm{bb}}$ and $b_{\mathrm{bb}}$; see Table 1$)$, dashed lines). Site observations (average $\pm \mathrm{SD}$, blue points and error bars) are also shown (see caption of Fig. 2 for details).

\section{A5 Tree mortality}

Results reported by van Mantgem et al. (2009) indicate an increasing trend in plant mortality rates $\left(M, \mathrm{yr}^{-1}\right)$ for Pacific Northwest forests, with $M$ growing from $\approx 1 \% \mathrm{yr}^{-1}$ in 2000 towards $\approx 1.5 \% \mathrm{yr}^{-1}$ in 2010. In CLM, a default rate of $M=$ $2 \% \mathrm{yr}^{-1}$ is used for all vegetation types, which was found to be excessive at Wind River, leading to a reduced modeled forest biomass. $M=1.5 \% \mathrm{yr}^{-1}$ was found to yield results closer to site observations and was therefore adopted in this study.

\section{A6 Temperature sensitivity coefficient $\left(Q_{10}\right)$}

The effect of temperature on maintenance respiration (component of autotrophic respiration) in CLM is calculated via a $Q_{10}$ formulation, in which the base rate of maintenance respiration is multiplied by $Q_{10}^{\left(T_{\mathrm{a}}-T_{\text {ref }}\right) / 10}$, where $Q_{10}$ is a temperature sensitivity coefficient, $T_{\mathrm{a}}$ is air temperature, and $T_{\mathrm{ref}}$ is a reference temperature. For the maintenance respiration cost for live fine roots, soil temperature at the respective soil layer ( $\left.T_{\mathrm{s}, i}\right)$ is used instead of $T_{\mathrm{a}}$. Similarly, the effect of temperature on decomposition (and therefore on heterotrophic respiration) is also calculated via a $Q_{10}$ formulation, in which the base rates of decomposition are multiplied by $Q_{10}^{\left(T_{\mathrm{s}, i}-T_{\mathrm{ref}}\right) / 10}$. In CLM, a default $Q_{10}$ of 1.5 is used for both maintenance respiration and decomposition. However, nighttime $\mathrm{CO}_{2}$ flux measurements above the canopy at Wind River, which would include the sum of autotrophic and heterotrophic respiration, indicate a $Q_{10}$ of 2.49 (Misson et al., 2007). By adjusting CLM's $Q_{10}$ to 2.5 for both maintenance respiration and decomposition, the seasonal behavior of ecosystem respiration better corresponded with observed values. This was especially the case for heterotrophic respiration, reducing the model overestimation during winter and the model underestimation during summer.

\section{A7 Soil hydraulic properties}

Initial runs indicated poor performance of CLM in the simulation of soil water content at the Wind River site (strong dry bias), which resulted in an unrealistic down-regulation of GPP due to soil moisture stress late in the dry summer season. When using the original soil hydraulic properties from CLM4.0 the results were greatly improved, with a wetter soil and a reduction of the unrealistic soil moisture stress. The observed improvement was likely related to a smaller subsurface runoff in CLM4.0 and consequently greater water retention in the soil. In CLM, subsurface runoff is proportional to a term representing the maximum drainage when the water table depth is at the surface $\left(q_{\mathrm{drai}}^{\max }\right)$. In CLM4.0, $q_{\text {drai }}^{\max }=0.0055 \mathrm{~kg} \mathrm{~m}^{-2} \mathrm{~s}^{-1}$, while in CLM4.5 $q_{\mathrm{drai}}^{\max }=10 \sin \beta \mathrm{kg} \mathrm{m}^{-2} \mathrm{~s}^{-1}$, where $\beta$ is the mean grid cell topographic slope. Even for a small $1^{\circ}$ slope, $q_{\text {drai }}^{\max }$ is significantly larger than in CLM4.0 $\left(0.1745 \mathrm{~kg} \mathrm{~m}^{-2} \mathrm{~s}^{-1}\right)$. The soil hydraulic properties from CLM4.0 were therefore used in this study.

\section{A8 Root distribution}

In CLM, root distribution over soil depth is calculated as in Eq. (4). Root fraction $\left(r_{i}\right)$ in combination with a plant wilting factor $\left(w_{i}\right.$, Eq. 5$)$ for each soil layer $i$ is used to calculate an integrated soil moisture stress parameter in CLM, $\beta_{t}$ (Eq. 3), which down-regulates stomatal conductance in the model (Eq. 2).

Shaw et al. (2004) provide a good description of rooting depth at Wind River: "Plant roots are concentrated above $50 \mathrm{~cm}$ in soil profiles; however, roots as deep as $2.05 \mathrm{~m}$ have been observed in younger forests growing on nearly identical soils (T. Hinckley, personal communication). Many coarse roots of Douglas fir extend to depths greater than $1.0 \mathrm{~m}$. Tipup mounds of windthrown western hemlock trees typically have a classic flat root plate indicative of shallow rooting" (Douglas fir and western hemlock are the dominant species at the site). With the default NETT PFT root distribution parameters in Eq. (4) $\left(r_{\mathrm{a}}=7 \mathrm{~m}^{-1}\right.$ and $\left.r_{\mathrm{b}}=2 \mathrm{~m}^{-1}\right)$, the total root fraction in the top 46 and $130 \mathrm{~cm}$ of soil is 78 and $96 \%$, respectively (note the small fraction of roots at depths below $1.3 \mathrm{~m}, 4 \%$ ). The site description above (Shaw et al., 2004) 

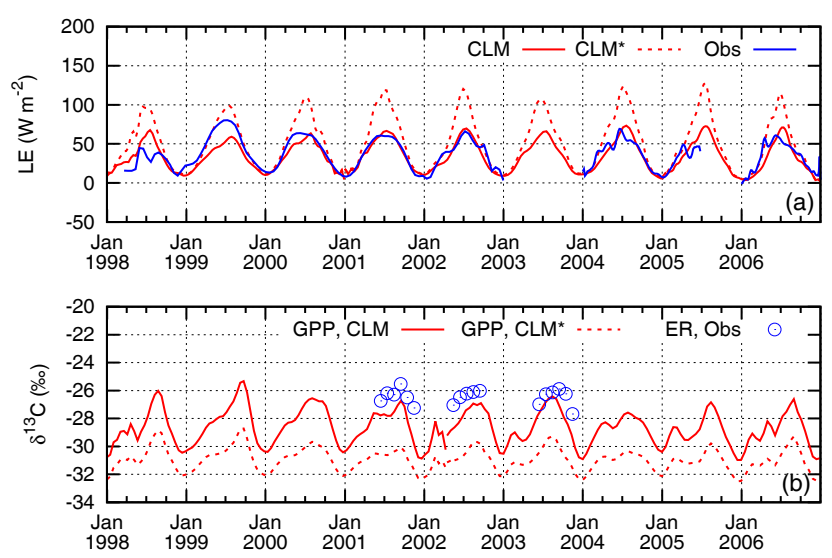

Figure A2. Modeled latent heat flux (a) and $\delta^{13} \mathrm{C}$ of gross primary production (b, lines) for 1998-2006. The curves presented correspond to Bézier-smoothed daily averages as in Figs. 3 and 5. Results from two model runs are presented: CLM (calibrated model, solid red lines) and $\mathrm{CLM}^{*}$ (calibrated model using the default stomatal conductance parameters ( $m_{\mathrm{bb}}$ and $b_{\mathrm{bb}}$; see Table 1$)$, dashed red lines). The blue line and circles correspond to site observations. The circles in panel (b) are the monthly averages of $\delta^{13} \mathrm{C}_{\mathrm{ER}}$ reported by Lai et al. (2005).

suggests that the default parameters are inadequate at Wind River, resulting in a too-shallow rooting profile.

In this study the NETT PFT $r_{\mathrm{b}}$ parameter was changed to $1 \mathrm{~m}^{-1}$ (default CLM value for broadleaf evergreen temperate tree PFT), shifting roots towards deeper soil layers, in order to make water stored at deeper soil layers available to the trees and, along with the changes in the soil hydraulic properties discussed in Appendix A7, reduce the excessive late-summer soil moisture stress and down-regulation of GPP in the model. With the adjusted $r_{\mathrm{b}}$ parameter, the total root fraction in the top 46 and $130 \mathrm{~cm}$ of soil is 67 and $86 \%$, respectively ( $14 \%$ below $1.3 \mathrm{~m}$ ), which seems more reasonable based on Shaw et al. (2004) and the fact that Douglas fir trees at the site are about 500 years old and $40-65 \mathrm{~m}$ tall. The adjustment of soil moisture stress in CLM via root distribution was therefore physically justified.

The plant wilting factor, $w_{i}$, offers an additional path for adjustment of the simulated soil moisture stress, but it was not investigated in this study.

\section{A9 Stomatal conductance}

In CLM, leaf stomatal conductance is calculated based on the Ball-Berry model as described by Collatz et al. (1991) and implemented by Sellers et al. (1996) in the SiB2 model (see Eq. 2). The default values set for the parameters $m_{\mathrm{bb}}$ and $b_{\mathrm{bb}}$ in CLM for $\mathrm{C}_{3}$ plants ( 9 and $10 \mathrm{mmol} \mathrm{m}^{-2}$ leaf $\mathrm{s}^{-1}$, respectively) were found to be inadequate at Wind River, leading to a significant overestimation of latent heat fluxes due to excessive plant transpiration (after the adjustments discussed in the aforementioned sections, which resulted in higher forest pro-

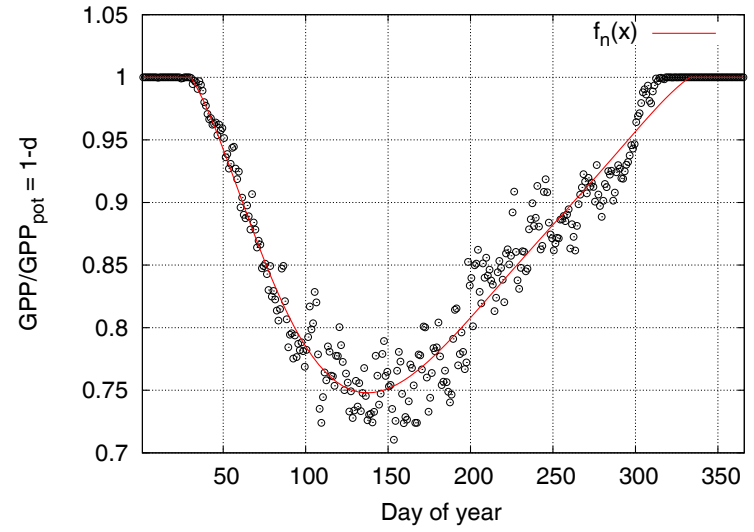

Figure A3. Modeled fraction of potential GPP (GPP/GPP $\left.{ }_{p o t}\right)$. Data points correspond to daily means averaged over 18502006 (calibrated CLM simulation). The fitted curve is $f_{n}(x=$ day of year $)=-1.39697 \times 10^{-14} x^{6}+1.71948 \times 10^{-11} x^{5}-8.26883 \times$ $10^{-9} x^{4}+1.90682 \times 10^{-6} x^{3}-1.97639 \times 10^{-4} x^{2}+0.0055728 x+$ 0.966272 for $31 \leq x \leq 332$ and $f_{n}(x)=1$ elsewhere. Note that GPP/GPP ${ }_{\text {pot }}=1-d$, where $d$ is the nitrogen down-regulation factor as defined in Eq. (9) within text.

ductivity). These default parameter values were established based on the values used in the SiB2 model (Sellers et al., 1996). In SiB2, however, a distinction was made for coniferous forests $\left(m_{\mathrm{bb}}=6\right)$ but was not carried over to CLM. Observations reported in the literature support this lower $m_{\mathrm{bb}}$ value for conifers (see for example the survey by Williams et al., 2004, Table 6.3, and Miner et al., 2017, Fig. 1). Conversely, $b_{\mathrm{bb}}$ values reported in the literature are highly variable (1-400 $\mathrm{mmol} \mathrm{m}^{-2}$ leaf $\mathrm{s}^{-1}$ in the survey by Barnard and Bauerle, 2013, for a broad range of plant species). In CLM4.0, the default $b_{\mathrm{bb}}$ for $\mathrm{C}_{3}$ plants is significantly smaller than in CLM4.5 ( 2 vs. $10 \mathrm{mmol} \mathrm{m}^{-2}$ leaf s $^{-1}$ ) (Oleson et al., 2010). Values of $m_{\mathrm{bb}}=6$ and $b_{\mathrm{bb}}=5 \mathrm{mmol} \mathrm{m}^{-2}$ leaf s $\mathrm{s}^{-1}$ were found to greatly improve the modeled latent heat fluxes at the Wind River site and were therefore adopted in this study. The updated values also resulted in a great improvement in the simulation of $\delta^{13} \mathrm{C}$ of leaves, SOM, and GPP. Figures A1 and A2 illustrate the impact of the stomatal conductance parameters on model performance, particularly in regards to latent heat fluxes and photosynthetic ${ }^{13} \mathrm{C}$ discrimination.

It is important to highlight that the default nitrogen limitation scheme was used in the simulations. As discussed in Sect. 2.1, this scheme makes CLM a partially coupled model in respect to net leaf photosynthesis and stomatal conductance: while the potential GPP is down-regulated in response to nitrogen availability, stomatal conductance remains consistent with potential net leaf photosynthesis $\left(A_{\mathrm{n}}\right)$. With this structure, CLM is expected to overestimate plant transpiration and photosynthetic ${ }^{13} \mathrm{C}$ discrimination. The calibration of the Ball-Berry stomatal conductance parameters discussed above, especially the significant reduction 

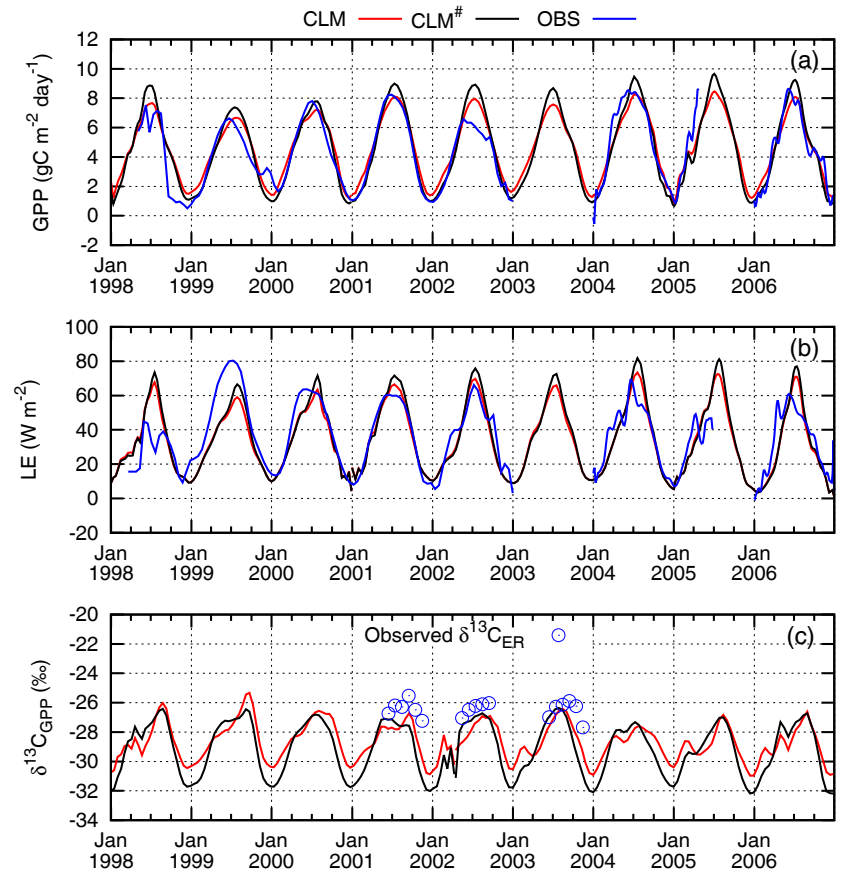

Figure A4. Modeled gross primary production (a), latent heat flux (b), and $\delta^{13} \mathrm{C}$ of gross primary production (c) for 1998-2006. The curves presented correspond to Bézier-smoothed daily averages as in Figs. 3 and 5. Results from two model runs are presented: CLM (calibrated model, red lines) and CLM $^{\#}$ (calibrated model using $m_{\mathrm{bb}}=9$ and the alternative nitrogen limitation scheme discussed in Appendix A9, black lines). In CLM ${ }^{\#}, V_{\text {cmax25 }}$ was multiplied by a seasonally varying nitrogen down-regulation factor, calculated based on the mean (1850-2006) seasonal cycle of $\mathrm{GPP} / \mathrm{GPP}_{\text {pot }}=1-d$ in the CLM run $\left(f_{n}(x)\right.$ in Fig. A3) subtracted by 0.35 (manual adjustment applied to avoid excessive productivity during the transient simulation). Blue lines and circles correspond to site observations. The circles in panel (c) are the monthly averages of $\delta^{13} \mathrm{C}_{\mathrm{ER}}$ reported by Lai et al. (2005).

of $m_{\mathrm{bb}}$ from 9 to 6 , must also have compensated for this structural issue within the model. Note that nitrogen downregulation is significant at Wind River, peaking at $\sim 0.25$ $\left(\mathrm{GPP} / \mathrm{GPP}_{\text {pot }}=0.75\right)$ in May (Fig. A3).

When using the default nitrogen limitation scheme in CLM, the modeled ${ }^{13} \mathrm{C}$ discrimination values reported by Raczka et al. (2016) for the Niwot Ridge AmeriFlux site (also a coniferous forest site) were significantly overestimated, i.e., $\delta^{13} \mathrm{C}$ values of GPP and biomass were significantly smaller than observations. To improve the simulation, Raczka et al. (2016) removed the post-photosynthetic nitrogen down-regulation of $A_{\mathrm{n}}$ and $\operatorname{GPP}_{\text {pot }}(d=0$; see Eq. 9) and included a foliar nitrogen-limiting factor in the calculation of $V_{\text {cmax25 }}$, making the model fully coupled in respect to net leaf photosynthesis and stomatal conductance. With this configuration, their simulation of ${ }^{13} \mathrm{C}$ discrimination improved significantly, but the values still presented a small overestimation in respect to the site observations. According to Raczka
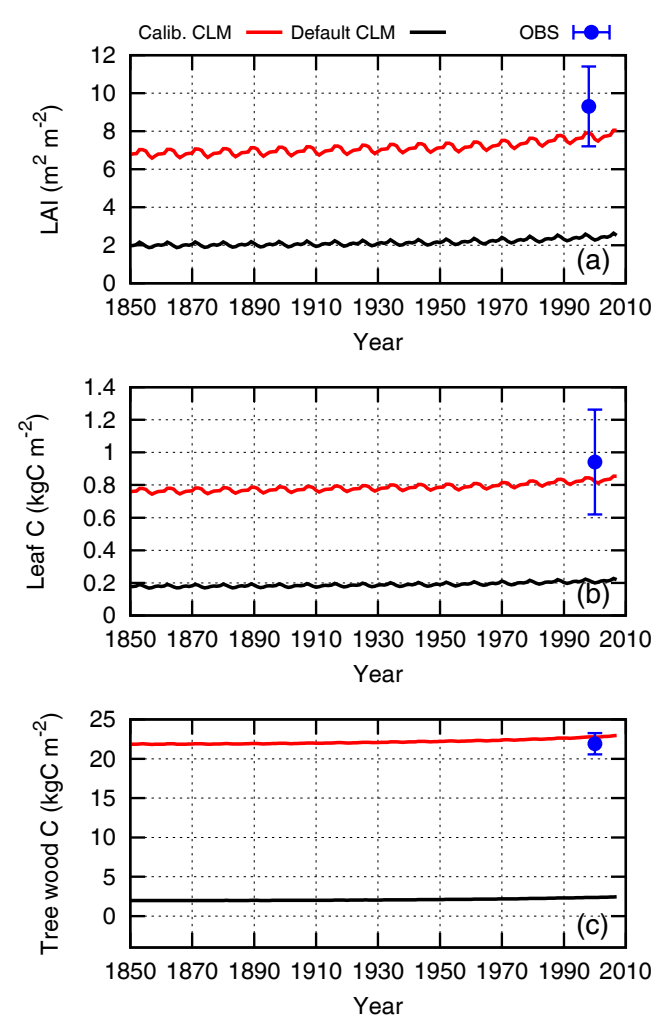

Figure A5. Comparison of CLM performance at Wind River when using default, "out-of-the-box" parameters (black lines) and calibrated parameters (red lines). Modeled values correspond to annual averages. Observations (average $\pm \mathrm{SD}$, blue points and error bars) are from the AmeriFlux database (based on Thomas and Winner, 2000, and Harmon et al., 2004).

et al. (2016), overestimation of $g_{\mathrm{s}}$ due to an inadequate $m_{\mathrm{bb}}$ value (too high) could be a reason for the mismatch (they used the default value of 9 in their simulation).

The alternative nitrogen limitation scheme (via $V_{\text {cmax } 25}$ down-regulation, as in Raczka et al., 2016) was also investigated here. The simulation of LE, GPP, and ${ }^{13} \mathrm{C}$ discrimination when using this configuration and the default $m_{\mathrm{bb}}$ value of 9 was found to be similar to the results when using the default nitrogen limitation scheme and $m_{\mathrm{bb}}=6$ (Fig. A4). The results in Fig. A4 indicate that the calibration of $m_{\mathrm{bb}}$ from 9 to 6 represents a tradeoff with the approach to nutrient limitation, compensating for elevated, nitrogen-unlimited (potential) net leaf photosynthesis used in the calculation of $g_{\text {s. }}$.

\section{A10 CLM performance: default vs. calibrated parameters}

In order to illustrate the effect of altering the model parameters discussed in this Appendix (see summary of changes in Table 1), Figs. A5 and A6 compare the performance of CLM for key model outputs when using "out-of-the-box" parame- 

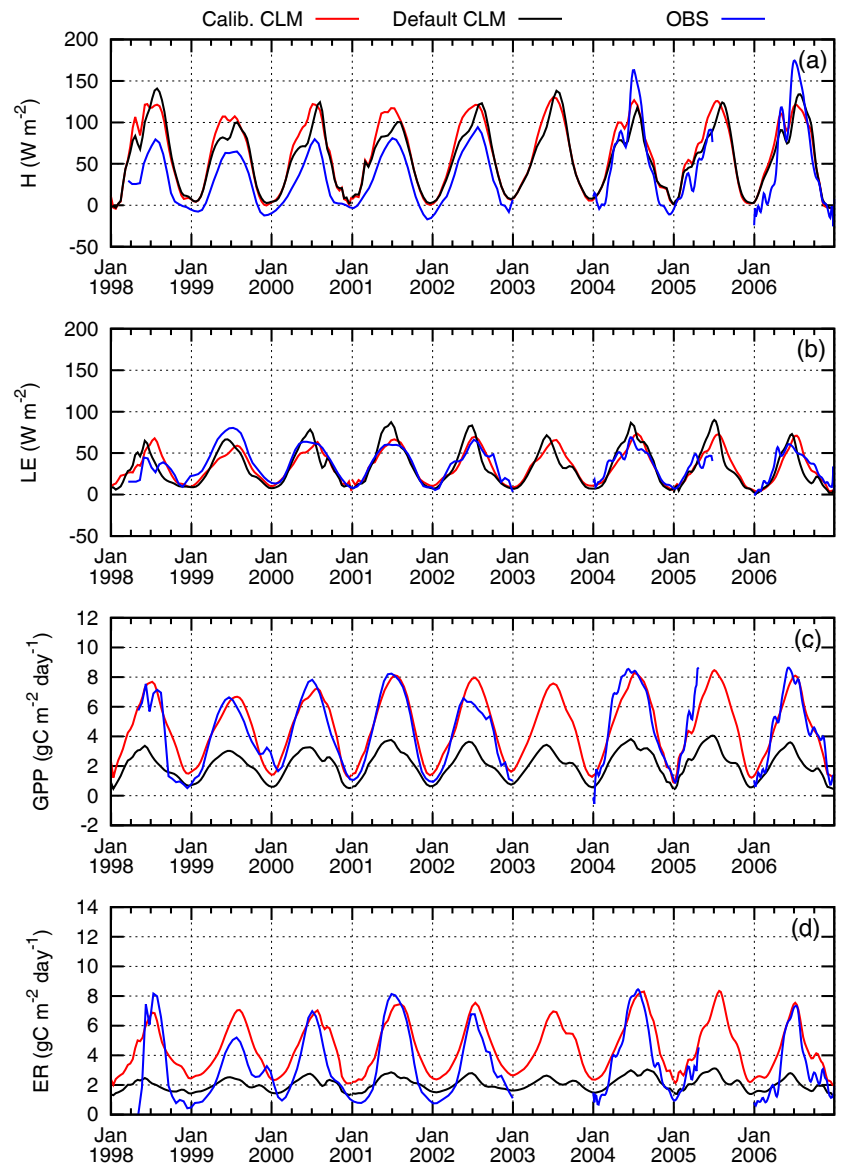

Figure A6. Comparison of CLM performance at Wind River when using default, "out-of-the-box" parameters (black lines) and calibrated parameters (red lines). Observations (blue lines) are from the AmeriFlux database. For a clearer visualization, the data presented correspond to Bézier-smoothed daily averages as in Fig. 3.

ters and calibrated parameters. Note the significant improvement in the simulation of LAI, biomass, and $\mathrm{CO}_{2} / \mathrm{H}_{2} \mathrm{O}$ fluxes. 
Competing interests. The authors declare that they have no conflict of interest.

Acknowledgements. This research was supported by the US Department of Energy's Office of Science, Terrestrial Ecosystem Science Program, under award number DE-SC0010624. BMR and DRB were supported by the US Department of Energy's Office of Science, Terrestrial Ecosystem Science Program, under award number DE-SC0010625. PET was supported by the US Department of Energy's Office of Science, Biological and Environmental Research, Accelerated Climate Modeling for Energy project. We acknowledge the Wind River Field Station AmeriFlux site (US-Wrc, PIs: Kenneth Bible, Sonia Wharton) for its data records. Funding for AmeriFlux data resources was provided by the US Department of Energy's Office of Science. Data and logistical support were also provided by the US Forest Service Pacific Northwest Research Station. We gratefully acknowledge the comments and suggestions of the editor and three anonymous reviewers, which have greatly improved our paper.

Edited by: Andreas Ibrom

Reviewed by: three anonymous referees

\section{References}

Alden, C. B., Miller, J. B., and White, J. W. C.: Can bottom-up ocean $\mathrm{CO}_{2}$ fluxes be reconciled with atmospheric ${ }^{13} \mathrm{C}$ observations?, Tellus B, 62, 369-388, 2010.

Aranibar, J. N., Berry, J. A., Riley, W. J., Pataki, D. E., Law, B. E., and Ehleringer, J. R.: Combining meteorology, eddy fluxes, isotope measurements, and modeling to understand environmental controls of carbon isotope discrimination at the canopy scale, Global Change Biol., 12, 710-730, 2006.

Baldocchi, D., Falge, E., Gu, L., Olson, R., Hollinger, D., Running, S., Anthoni, P., Bernhofer, C., Davis, K., Evans, R., Fuentes, J., Goldstein, A., Katul, G., Law, B., Lee, X., Malhi, Y., Meyers, T., Munger, W., Oechel, W., Paw U, K. T., Pilegaard, K., Schmid, H. P., Valentini, R., Verma, S., Vesala, T., Wilson, K., and Wofsy, S.: FLUXNET: a new tool to study the temporal and spatial variability of ecosystem-scale carbon dioxide, water vapor, and energy flux densities, B. Am. Meteorol. Soc., 82, 2415-2434, 2001.

Barnard, D. M. and Bauerle, W. L.: The implications of minimum stomatal conductance on modeling water flux in forest canopies, J. Geophys. Res.-Biogeo., 118, 1322-1333, 2013.

Barr, A., Ricciuto, D., Schaefer, K., Richardson, A., Agarwal, D., Thornton, P., Davis, K., Jackson, B., Cook, R., Hollinger, D., Van Ingen, C., Amiro, B., Andrews, A., Arain, M., Baldocchi, D., Black, T., Bolstad, P., Curtis, P., Desai, A., Dragoni, D., Flanagan, L., Gu, L., Katul, G., Law, B., Lafleur, P., Margolis, H., Matamala, R., Meyers, T., McCaughey, J., Monson, R., Munger, J., Oechel, W., Oren, R., Roulet, N., Torn, M., and Verma, S.: NACP site: tower meteorology, flux observations with uncertainty, and ancillary data, ORNL Distributed Active Archive Center, https://doi.org/10.3334/ORNLDAAC/1178, 2013.

Boisvenue, C. and Running, S. W.: Simulations show decreasing carbon stocks and potential for carbon emissions in Rocky
Mountain forests over the next century, Ecol. Appl., 20, 1302 1319, 2010.

Bowling, D. R., Pataki, D. E., and Randerson, J. T.: Carbon isotopes in terrestrial ecosystem pools and $\mathrm{CO}_{2}$ fluxes, New Phytol., 178, 24-40, 2008.

Brüggemann, N., Gessler, A., Kayler, Z., Keel, S. G., Badeck, F., Barthel, M., Boeckx, P., Buchmann, N., Brugnoli, E., Esperschütz, J., Gavrichkova, O., Ghashghaie, J., Gomez-Casanovas, N., Keitel, C., Knohl, A., Kuptz, D., Palacio, S., Salmon, Y., Uchida, Y., and Bahn, M.: Carbon allocation and carbon isotope fluxes in the plant-soil-atmosphere continuum: a review, Biogeosciences, 8, 3457-3489, https://doi.org/10.5194/bg-8-34572011, 2011.

Burke, E. J., Brown, S. J., and Christidis, N.: Modeling the recent evolution of global drought and projections for the twenty-first century with the Hadley Centre Climate Model, J. Hydrometeorol., 7, 1113-1125, 2006.

Collatz, G. J., Ball, J. T., Grivet, C., and Berry, J. A.: Physiological and environmental regulation of stomatal conductance, photosynthesis and transpiration: a model that includes a laminar boundary layer, Agr. Forest Meteorol., 54, 107-136, 1991.

Dai, A.: Increasing drought under global warming in observations and models, Nat. Clim. Change, 3, 52-58, 2013.

Damour, G., Simonneau, T., Cochard, H., and Urban, L.: An overview of models of stomatal conductance at the leaf level, Plant Cell Environ., 33, 1419-1438, 2010.

Farquhar, G. D. and Richards, R. A.: Isotopic composition of plant carbon correlates with water-use efficiency of wheat genotypes, Aust. J. Plant Physiol., 11, 539-552, 1984.

Farquhar, G. D., Ehleringer, J. R., and Hubick, K. T.: Carbon isotope discrimination and photosynthesis, Annu. Rev. Plant Phys., 40, 503-537, 1989.

Fessenden, J. E. and Ehleringer, J. R.: Temporal variation in $\delta^{13} \mathrm{C}$ of ecosystem respiration in the Pacific Northwest: links to moisture stress, Oecologia, 136, 129-136, 2003.

Francey, R. J., Allison, C. E., Etheridge, D. M., Trudinger, C. M., Enting, I. G., Leuenberger, M., Langenfelds, R. L., Michel, E., and Steele, L. P.: A 1000-year high precision record of $\delta^{13} \mathrm{C}$ in atmospheric $\mathrm{CO}_{2}$, Tellus B, 51, 170-193, 1999.

Fyfe, J. C., Derksen, C., Mudryk, L., Flato, G. M., Santer, B. D., Swart, N. C., Molotch, N. P., Zhang, X., Wan, H., Arora, V. K., Scinocca, J., and Jiao, Y.: Large near-term projected snowpack loss over the western United States, Nat. Commun., 8, 14996, https://doi.org/10.1038/ncomms14996, 2017.

Ghimire, B., Riley, W. J., Koven, C. D., Mu, M., and Randerson, J. T.: Representing leaf and root physiological traits in CLM improves global carbon and nitrogen cycling predictions, J. Adv. Model. Earth Syst., 8, 598-613, 2016.

Harmon, M. E., Bible, K., Ryan, M. G., Shaw, D. C., Chen, H., Klopatek, J., and Li, X.: Production, respiration, and overall carbon balance in an old-growth Pseudotsuga-Tsuga forest ecosystem, Ecosystems, 7, 498-512, 2004.

Hudiburg, T. W., Law, B. E., and Thornton, P. E.: Evaluation and improvement of the Community Land Model (CLM4) in Oregon forests, Biogeosciences, 10, 453-470, https://doi.org/10.5194/bg-10-453-2013, 2013.

Keeling, C. D.: The Suess effect: ${ }^{13}$ Carbon- ${ }^{14}$ Carbon interrelations, Environ. Int., 2, 229-300, 1979. 
Keeling, C. D., Piper, S. C., Bacastow, R. B., Wahlen, M., Whorf, T. P., Heimann, M., and Meijer, H. A.: Atmospheric $\mathrm{CO}_{2}$ and ${ }^{13} \mathrm{CO}_{2}$ exchange with the terrestrial biosphere and oceans from 1978 to 2000: observations and carbon cycle implications, in: A history of atmospheric $\mathrm{CO}_{2}$ and its effects on plants, animals, and ecosystems, Ecological Studies, 177, edited by: Ehleringer, J. R., Cerling, T. E., and Dearing, M. D., Springer Science and Business Media Inc., New York, USA, 83-113, 2005.

Keller, K. M., Lienert, S., Bozbiyik, A., Stocker, T. F., Churakova (Sidorova), O. V., Frank, D. C., Klesse, S., Koven, C. D., Leuenberger, M., Riley, W. J., Saurer, M., Siegwolf, R., Weigt, R. B., and Joos, F.: 20th century changes in carbon isotopes and water-use efficiency: tree-ring-based evaluation of the CLM4.5 and LPX-Bern models, Biogeosciences, 14, 26412673, https://doi.org/10.5194/bg-14-2641-2017, 2017.

Klopatek, J. M.: Litterfall and fine root biomass contribution to nutrient dynamics in second- and old-growth Douglas-fir ecosystems, Plant Soil, 294, 157-167, 2007.

Kluzek, E.: CESM research tools: CLM4.5 in CESM1.2.0 user's guide documentation, available at: http://www.cesm.ucar.edu/ (last access: 21 September 2017), 2013.

Lai, C.-T., Ehleringer, J. R., Schauer, A. J., Tans, P. P., Hollinger, D. Y., Paw U, K. T., Munger, J. W., and Wofsy, S. C.: Canopy-scale delta13C of photosynthetic and respiratory $\mathrm{CO}_{2}$ fluxes: observations in forest biomes across the United States, Global Change Biol., 11, 633-643, 2005.

Mao, J., Ricciuto, D. M., Thornton, P. E., Warren, J. M., King, A. W., Shi, X., Iversen, C. M., and Norby, R. J.: Evaluating the Community Land Model in a pine stand with shading manipulations and ${ }^{13} \mathrm{CO}_{2}$ labeling, Biogeosciences, 13, 641-657, https://doi.org/10.5194/bg-13-641-2016, 2016.

Medlyn, B. E., Duursma, R. A., Eamus, D., Ellsworth, D. S., Prentice, I. C., Barton, C. V. M., Crous, K. Y., de Angelis, P., Freeman, M., and Wingate, L.: Reconciling the optimal and empirical approaches to modelling stomatal conductance, Global Change Biol., 17, 2134-2144, 2011.

Meinshausen, M., Smith, S. J., Calvin, K. V., Daniel, J. S., Kainuma, M. L. T., Lamarque, J.-F., Matsumoto, K., Montzka, S. A., Raper, S. C. B., Riahi, K., Thomson, A. M., Velders, G. J. M., and van Vuuren, D.: The RCP greenhouse gas concentrations and their extension from 1765 to 2300, Climatic Change, 109, 213-241, 2011.

Metcalfe, D. B., Ricciuto, D., Palmroth, S., Campbell, C., Hurry, V., Mao, J., Keel, S. G., Linder, S., Shi, X., Näsholm, T., Ohlsson, K. E. A., Blackburn, M., Thornton, P. E., and Oren, R.: Informing climate models with rapid chamber measurements of forest carbon uptake, Global Change Biol., 23, 2130-2139, 2017.

Miner, G. L., Bauerle, W. L., and Baldocchi, D. D.: Estimating the sensitivity of stomatal conductance to photosynthesis: a review, Plant Cell Environ., 40, 1214-1238, 2017.

Misson, L., Baldocchi, D. D., Black, T. A., Blanken, P. D., Brunet, Y., Curiel Yuste, J., Dorsey, J. R., Falk, M., Granier, A., Irvine, M. R., Jarosz, N., Lamaud, E., Launiainen, S., Law, B. E., Longdoz, B., Loustau, D., McKay, M., Paw U, K. T., Vesala, T., Vickers, D., Wilson, K. B., and Goldstein, A. H.: Partitioning forest carbon fluxes with overstory and understory eddy-covariance measurements: a synthesis based on FLUXNET data, Agr. Forest Meteorol., 144, 14-31, 2007.
Monteith, J. L.: Evaporation and environment, in: The state and movement of water in living organisms, 19th Symposium of the Society on Experimental Biology, Academic Press, New York, USA, 205-234, 1964.

Oleson, K. W., Lawrence, D. M., Bonan, G. B., Flanner, M. G., Kluzek, E., Lawrence, P. J., Levis, S., Swenson, S. C., Thornton, P. E., Dai, A., Decker, M., Dickinson, R., Feddema, J., Heald, C. L., Hoffman, F., Lamarque, J.-F., Mahowald, N., Niu, G.-Y., Qian, T., Randerson, J., Running, S., Sakaguchi, K., Slater, A., Stöckli, R., Wang, A., Yang, Z.-L., Zeng, X., and Zeng, X.: Technical description of version 4.0 of the Community Land Model (CLM), NCAR Earth System Laboratory - Climate and Global Dynamics Division, Boulder, Colorado, USA, Tech. Rep. TN478+STR, 2010.

Oleson, K. W., Lawrence, D. M., Bonan, G. B., Drewniak, B., Huang, M., Koven, C. D., Levis, S., Li, F., Riley, W. J., Subin, Z. M., Swenson, S. C., Thornton, P. E., Bozbiyik, A., Fisher, R., Heald, C. L., Kluzek, E., Lamarque, J.-F., Lawrence, P. J., Leung, L. R., Lipscomb, W., Muszala, S., Ricciuto, D. M., Sacks, W., Sun, Y., Tang, J., and Yang, Z.-L.: Technical description of version 4.5 of the Community Land Model (CLM), NCAR Earth System Laboratory - Climate and Global Dynamics Division, Boulder, Colorado, USA, Tech. Rep. TN-503+STR, http://www.cesm.ucar.edu/models/cesm1.2/clm/ CLM45_Tech_Note.pdf (last access: 27 September 2017), 2013.

Parker, G. G., Harmon, M. E., Lefsky, M. A., Chen, J., van Pelt, R., Weiss, S. B., Thomas, S. C., Winner, W. E., Shaw, D. C., and Franklin, J. F.: Three-dimensional structure of an old-growth Pseudotsuga-Tsuga canopy and its implications for radiation balance, microclimate, and gas exchange, Ecosystems, 7, 440-453, 2004.

Parkinson, J. A.: Nitrogen and phosphorus retranslocation from needles of Douglas-fir growing on three site types, Master's thesis, University of British Columbia, Vancouver, Canada, 1983.

Pataki, D. E., Ehleringer, J. R., Flanagan, L. B., Yakir, D., Bowling, D. R., Still, C. J., Buchmann, N., Kaplan, J. O., and Berry, J. A.: The application and interpretation of Keeling plots in terrestrial carbon-cycle research, Global Biogeochem. Cy., 17, 1022, https://doi.org/10.1029/2001GB001850, 2003.

Prein, A. F., Holland, G. J., Rasmussen, R. M., Clark, M. P., and Tye, M. R.: Running dry: the U.S. Southwest's drift into a drier climate state, Geophys. Res. Lett., 43, 1272-1279, 2016.

Raczka, B., Duarte, H. F., Koven, C. D., Ricciuto, D., Thornton, P. E., Lin, J. C., and Bowling, D. R.: An observational constraint on stomatal function in forests: evaluating coupled carbon and water vapor exchange with carbon isotopes in the Community Land Model (CLM4.5), Biogeosciences, 13, 5183-5204, https://doi.org/10.5194/bg-13-5183-2016, 2016.

Reichstein, M., Falge, E., Baldocchi, D., Papale, D., Aubinet, M., Berbigier, P., Bernhofer, C., Buchmann, N., Gilmanov, T., Granier, A., Grnwald, T., Havrnkov, K., Ilvesniemi, H., Janous, D., Knohl, A., Laurila, T., Lohila, A., Loustau, D., Matteucci, G., Meyers, T., Miglietta, F., Ourcival, J.-M., Pumpanen, J., Rambal, S., Rotenberg, E., Sanz, M., Tenhunen, J., Seufert, G., Vaccari, F., Vesala, T., Yakir, D., and Valentini, R.: On the separation of net ecosystem exchange into assimilation and ecosystem respiration: review and improved algorithm, Global Change Biol., 11, 1424-1439, 2005. 
Riley, W. J., Still, C. J., Torn, M. S., and Berry, J. A.: A mechanistic model of $\mathrm{H}_{2}^{18} \mathrm{O}$ and $\mathrm{C}^{18} \mathrm{OO}$ fluxes between ecosystems and the atmosphere: model description and sensitivity analyses, Global Biogeochem. Cy., 16, 1095, https://doi.org/10.1029/2002GB001878, 2002.

Sato, H., Kumagai, T., Takahashi, A., and Katul, G. G.: Effects of different representations of stomatal conductance response to humidity across the African continent under warmer $\mathrm{CO}_{2}$-enriched climate conditions, J. Geophys. Res.-Bio., 120, 979-988, 2015.

Schaefer, K., Collatz, G. J., Tans, P. P., Denning, A. S., Baker, I., Berry, J. A., Prihodko, L., Suits, N., and Philpott, A.: Combined Simple Biosphere/Carnegie-Ames-Stanford Approach terrestrial carbon cycle model, J. Geophys. Res., 113, G03034, https://doi.org/10.1029/2007JG000603, 2008.

Scholze, M., Kaplan, J. O., Knorr, W., and Heimann, M.: Climate and interannual variability of the atmospherebiosphere ${ }^{13} \mathrm{CO}_{2}$ flux, Geophys. Res. Lett., 30, 1097, https://doi.org/10.1029/2002GL015631, 2003.

Scholze, M., Ciais, P., and Heimann, M.: Modeling terrestrial ${ }^{13} \mathrm{C}$ cycling: climate, land use and fire, Global Biogeochem. Cy., 22, GB1009, https://doi.org/10.1029/2006GB002899, 2008.

Sellers, P. J., Randall, D. A., Collatz, G. J., Berry, J. A., Field, C. B., Dazlich, D. A., Zhang, C., Collelo, G. D., and Bounoua, L.: A revised land surface parameterization (SiB2) for atmospheric GCMs. Part I: model formulation, J. Climate, 9, 676-705, 1996.

Shaw, D. C., Franklin, J. F., Bible, K., Klopatek, J., Freeman, E., Greene, S., and Parker, G. G.: Ecological setting of the Wind River old-growth forest, Ecosystems, 7, 427-439, 2004.

Sheffield, J. and Wood, E. F.: Projected changes in drought occurrence under future global warming from multi-model, multiscenario, IPCC AR4 simulations, Clim. Dynam., 31, 79-105, 2008.

Spahni, R., Joos, F., Stocker, B. D., Steinacher, M., and Yu, Z. C.: Transient simulations of the carbon and nitrogen dynamics in northern peatlands: from the Last Glacial Maximum to the 21st century, Clim. Past, 9, 1287-1308, https://doi.org/10.5194/cp-91287-2013, 2013.

Sperry, J. S., Venturas, M. D., Anderegg, W. R. L., Mencuccini, M., Scott Mackay, D., Wang, Y., and Love, D. M.: Predicting stomatal responses to the environment from the optimization of photosynthetic gain and hydraulic cost, Plant Cell Environ., 40, 816-830, 2017.

Spies, T. A., Giesen, T. W., Swanson, F. J., Franklin, J. F., Lach, D., and Johnson, K. N.: Climate change adaptation strategies for federal forests of the Pacific Northwest, USA: ecological, policy, and socio-economic perspectives, Landscape Ecol., 25, 11851199, 2010.

Stocker, B. D., Roth, R., Joos, F., Spahni, R., Steinacher, M., Zaehle, S., Bouwman, L., Xu-Ri, and Prentice, I. C.: Multiple greenhouse-gas feedbacks from the land biosphere under future climate change scenarios, Nat. Clim. Change, 3, 666-672, 2013.

Suits, N. S., Denning, A. S., Berry, J. A., Still, C. J., Kaduk, J., Miller, J. B., and Baker, I. T.: Simulation of carbon isotope discrimination of the terrestrial biosphere, Global Biogeochem. Cy., 19, GB1017, https://doi.org/10.1029/2003GB002141, 2005.

Sun, Y., Gu, L. H., Dickinson, R. E., Norby, R. J., Pallardy, S. G., and Hoffman, F. M.: Impact of mesophyll diffusion on estimated global land $\mathrm{CO}_{2}$ fertilization, P. Natl. Acad. Sci. USA, 111, 15774-15779, 2014.
Swain, S. and Hayhoe, K.: CMIP5 projected changes in spring and summer drought and wet conditions over North America, Clim. Dynam., 44, 2737-2750, 2015.

Taylor, A. J., Lai, C.-T., Hopkins, F. M., Wharton, S., Bible, K., Xu, X., Phillips, C., Bush, S., and Ehleringer, J. R.: Radiocarbonbased partitioning of soil respiration in an old-growth coniferous forest, Ecosystems, 18, 459-470, 2015.

Thomas, S. C. and Winner, W. E.: Leaf area index of an old-growth Douglas-fir forest estimated from direct structural measurements in the canopy, Can. J. Forest Res., 30, 1922-1930, 2000.

Thornton, P. E. and Zimmermann, N. E.: An improved canopy integration scheme for a land surface model with prognostic canopy structure, J. Climate, 20, 3902-3923, 2007.

Thornton, P. E., Law, B. E., Gholz, H. L., Clark, K. L., Falge, E., Ellsworth, D. S., Goldstein, A. H., Monson, R. K., Hollinger, D., Falk, M., Chen, J., and Sparks, J. P.: Modeling and measuring the effects of disturbance history and climate on carbon and water budgets in evergreen needleleaf forests, Agr. Forest Meteorol., 113, 185-222, 2002.

Unsworth, M. H., Phillips, N., Link, T., Bond, B. J., Falk, M., Harmon, M. E., Hinckley, T. M., Marks, D., and Paw U, K. T.: Components and controls of water flux in an old-growth Douglas-firwestern hemlock ecosystem, Ecosystems, 7, 468-481, 2004.

van der Velde, I. R., Miller, J. B., Schaefer, K., Masarie, K. A., Denning, S., White, J. W. C., Tans, P. P., Krol, M. C., and Peters, W.: Biosphere model simulations of interannual variability in terrestrial ${ }^{13} \mathrm{C} /{ }^{12} \mathrm{C}$ exchange, Global Biogeochem. Cy., 27, 637-649, 2013.

van der Velde, I. R., Miller, J. B., Schaefer, K., van der Werf, G. R., Krol, M. C., and Peters, W.: Terrestrial cycling of ${ }^{13} \mathrm{CO}_{2}$ by photosynthesis, respiration, and biomass burning in SiBCASA, Biogeosciences, 11, 6553-6571, https://doi.org/10.5194/bg-116553-2014, 2014.

van Mantgem, P. J., Stephenson, N. L., Byrne, J. C., Daniels, L. D., Franklin, J. F., Fulé, P. Z., Harmon, M. E., Larson, A. J., Smith, J. M., Taylor, A. H., and Veblen, T. T.: Widespread increase of tree mortality rates in the western United States, Science, 323, 521-524, 2009.

Vidale, P.-L. and Stöckli, R.: Prognostic canopy air space solutions for land surface exchanges, Theor. Appl. Climatol., 80, 245-257, 2005.

Wehr, R. and Saleska, S. R.: An improved isotopic method for partitioning net ecosystem-atmosphere $\mathrm{CO}_{2}$ exchange, Agr. Forest Meteorol., 214-215, 515-531, 2015.

Wharton, S.: AmeriFlux US-Wrc Wind River Crane Site, https://doi.org/10.17190/AMF/1246114, 1998-2016.

Wharton, S., Schroeder, M., Bible, K., Falk, M., and Paw U, K.-T.: Stand-level gas-exchange responses to seasonal drought in very young versus old Douglas-fir forests of the Pacific Northwest, USA, Tree Physiol., 29, 959-974, 2009.

Wharton, S., Falk, M., Bible, K., Schroeder, M., and Paw U, K.: Old-growth $\mathrm{CO}_{2}$ flux measurements reveal high sensitivity to climate anomalies across seasonal, annual and decadal time scales, Agr. Forest Meteorol., 161, 1-14, 2012.

White, M. A., Thornton, P. E., Running, S. W., and Nemani, R. R.: Parameterization and sensitivity analysis of the BIOME-BGC terrestrial ecosystem model: net primary production controls, Earth Interact., 4, 1-80, 2000. 
Williams, M., Woodward, F. I., Baldocchi, D. D., and Ellsworth, D.: $\mathrm{CO}_{2}$ capture - leaf to landscape, chap. 6, in: Photosynthetic adaptation: chloroplast to landscape, Ecological Studies, 178, edited by: Smith, W. K., Vogelmann, T. C., and Critchley, C., Springer Science and Business Media Inc., New York, USA, 133-170, 2004.
Woodruff, D. R., Bond, B. J., and Meinzer, F. C.: Does turgor limit growth in tall trees?, Plant Cell Environ., 27, 229-236, 2004. 